\title{
A Single-Factor Consumption-Based Asset Pricing Model
}

DOI:

$10.1017 / \mathrm{S} 0022109018000819$

\section{Document Version}

Accepted author manuscript

Link to publication record in Manchester Research Explorer

\section{Citation for published version (APA):}

Delikouras, S., \& Kostakis, A. (2018). A Single-Factor Consumption-Based Asset Pricing Model. Journal of Financial and Quantitative Analysis, 54(2), 789-827. https://doi.org/10.1017/S0022109018000819

\section{Published in:}

Journal of Financial and Quantitative Analysis

\section{Citing this paper}

Please note that where the full-text provided on Manchester Research Explorer is the Author Accepted Manuscript or Proof version this may differ from the final Published version. If citing, it is advised that you check and use the publisher's definitive version.

\section{General rights}

Copyright and moral rights for the publications made accessible in the Research Explorer are retained by the authors and/or other copyright owners and it is a condition of accessing publications that users recognise and abide by the legal requirements associated with these rights.

\section{Takedown policy}

If you believe that this document breaches copyright please refer to the University of Manchester's Takedown Procedures [http://man.ac.uk/04Y6Bo] or contact uml.scholarlycommunications@manchester.ac.uk providing relevant details, so we can investigate your claim.

\section{OPEN ACCESS}




\title{
A Single-Factor Consumption-Based Asset Pricing Model*
}

\author{
Stefanos Delikouras ${ }^{\dagger}$ Alexandros Kostakis ${ }^{\ddagger}$
}

December 6, 2017

\begin{abstract}
We propose a single-factor asset pricing model based on an indicator function of consumption growth being less than its endogenous certainty equivalent. This certainty equivalent is derived from generalized disappointment aversion preferences, and it is located approximately one standard deviation below the conditional mean of consumption growth. Our single-factor model can explain the cross-section of expected returns for size, value, reversal, profitability, and investment portfolios at least as well as the Fama-French multi-factor models. Our results show strong empirical support for asymmetric preferences, and question the effectiveness of the smooth utility framework, which is traditionally used in consumption-based asset pricing.
\end{abstract}

Keywords: asset pricing, stock returns, consumption, disappointment aversion, indicator, certainty equivalent, risk aversion

JEL classification: D51, D91, E21, G12

\footnotetext{
*An earlier version of the paper was circulated under the title: "One-Factor Asset Pricing". This paper has benefited from the comments of Massimiliano Affinito, Daniele Bianchi, Michael Brennan, Tim Burch, Indraneel Chakraborty, Vidhi Chhaochharia, Ric Colacito, Robert Dittmar, Adam Faragó, Andrea Gamba, Gikas Hardouvelis, Alex Horenstein, Petri Jylha, Marcin Kacperczyk, Paul Karehnke, George Korniotis, Roman Kozhan, Alok Kumar, Marie Lambert, Alex Michaelides, David Miles, Paulo Santos Monteiro, Philippe Mueller, Cesare Robotti, Bryan Routledge, Christian Schlag, Maik Schmeling, David Schreindorfer, George Skiadopoulos, Peter Smith, Peter Spencer, Alex Stremme, Roméo Tédongap, John Thanassoulis, Fabio Trojani, Emmanuel Tsiritakis, Raman Uppal, Ansgar Walther, Michael Weber, Mike Wickens and seminar participants at Imperial College, Inquire UK, University of Miami, University of Piraeus, University of York, Warwick Business School, the 2015 Paris Financial Management Conference, the 2016 MFA Annual Meetings, the 3rd SAFE Asset Pricing Workshop, and the 14th Paris December Finance Meeting, the 2017 FMA Europe, WFA, and EFA Meetings.

${ }^{\dagger}$ Department of Finance, School of Business Administration, University of Miami, 514-L Jenkins Building, Coral Gables, FL 33124, email: sdelikouras@bus.umiami.edu

${ }^{\ddagger}$ Department of Accounting and Finance, Manchester Business School, University of Manchester, Booth Street West, Manchester, M15 6PB UK, email: alexandros.kostakis@manchester.ac.uk
} 


\title{
A Single-Factor Consumption-Based Asset Pricing Model
}

December 6, 2017

\begin{abstract}
We propose a single-factor asset pricing model based on an indicator function of consumption growth being less than its endogenous certainty equivalent. This certainty equivalent is derived from generalized disappointment aversion preferences, and it is located approximately one standard deviation below the conditional mean of consumption growth. Our single-factor model can explain the cross-section of expected returns for size, value, reversal, profitability, and investment portfolios at least as well as the Fama-French multi-factor models. Our results show strong empirical support for asymmetric preferences, and question the effectiveness of the smooth utility framework, which is traditionally used in consumption-based asset pricing.
\end{abstract}

Keywords: asset pricing, stock returns, consumption, disappointment aversion, indicator, certainty equivalent, risk aversion

JEL classification: D51, D91, E21, G12 


\section{Introduction}

Despite their universal importance, asset pricing models are usually characterized by a puzzling contradiction. On one hand, most of the empirical factor models that can successfully explain risk premia do not provide strong guidance with respect to the deep economic mechanism that drives expected returns. On the other hand, many models that are motivated by economic theory have limited empirical success.

For instance, according to the standard consumption-based framework (CCAPM) of Breeden (1979), expected returns across assets should be explained by their exposure to aggregate consumption risk. Specifically, Breeden shows that Merton's (1973) Intertemporal Capital Asset Pricing Model (ICAPM) pricing equation can be collapsed into a single-beta representation, where the expected excess return on any security is proportional to its covariance with aggregate consumption growth alone. Nevertheless, a number of studies have questioned the ability of consumption risk to explain equity premia and the cross-section of expected returns (e.g., Mehra and Prescott (1985), Liu, Whited, and Zhang (2009)). Further, recent efforts to introduce alternative measures of consumption risk (e.g., Parker and Julliard (2005), Jagannathan and Wang (2007), Savov (2011)) have been undermined by the implausibly high degree of risk aversion that these models still imply for the representative agent.

To address the poor performance of single-factor models like the CAPM or the CCAPM, empirical asset pricing models tend to employ an increasing number of return-generated factors (see the recent contributions of Fama and French (2015) and Hou, Xue, and Zhang (2016)). However, in most cases, these multi-factor models do not provide convincing arguments regarding the economic underpinnings of the proposed pricing factors, let alone data mining concerns (see Harvey, Liu, and Zhu (2015)).

Motivated by the empirical shortcomings of the traditional consumption model and the upward trend in the number of pricing factors, we propose a single-factor, consumption-based model featuring disappointment aversion, but second-order risk-neutrality, to explain the 
cross-section of expected stock returns. The only pricing factor in our model is an indicator function of consumption growth being less than its certainty equivalent. This certainty equivalent is derived from generalized disappointment aversion preferences (Gul (1991) and Routledge and Zin (2010)), and it is located approximately one standard deviation below the conditional mean of consumption growth. Using this single-factor model, we show that downside consumption risk alone, as proxied by the disappointment indicator, can rationalize both the level and the cross-sectional dispersion of expected returns.

The starting point for our single-factor model is disappointment aversion, which was firstly introduced by Gul (1991) and subsequently generalized by Routledge and Zin (2010). Under this axiomatic framework, investor utility over stochastic consumption exhibits three features: (i) it is defined over deviations from a reference point, (ii) it is steeper for losses than for gains, and (iii) the reference point for gains and losses is based on the certainty equivalent of consumption.

These characteristics imply that disappointment aversion preferences are described by utility functions with a kink, exhibiting first-order risk aversion (Segal and Spivak (1990)), contrary to standard preferences specifications that employ smooth utility functions characterized by second-order risk aversion (e.g., CRRA or CARA). Moreover, in the disappointment aversion framework, the location of the kink is endogenously determined rather than being exogenously imposed in an ad hoc fashion, as it is the case with prospect theory specifications (see Barberis, Huang, and Santos (2001)).

Despite its theoretical tractability, the implementation of the disappointment model is quite challenging. Specifically, in the generalized disappointment model of Routledge and Zin (2010), preferences are nonseparable across time, and hence the resulting stochastic discount factor (SDF) is a function of consumption growth as well as lifetime utility, which is unobservable. The presence of unobservable lifetime utility in the disappointment aversion SDF impedes its empirical estimation. Following Delikouras (2017), we circumvent this problem by assuming that consumption growth is predictable and homoscedastic. Thus, we 
are able to derive explicit solutions for lifetime utility and the disappointment aversion SDF in terms of observable consumption growth alone.

In contrast to the highly nonlinear model proposed by Delikouras (2017), we propose a model where the representative investor is disappointment averse but second-order riskneutral. In other words, her preferences are characterized by a piecewise linear function with a kink. As a result, our model is quite simple and consists of a single asset pricing factor: the indicator of consumption growth being less than its certainty equivalent. The implication of our model is that risky assets yield premia as compensation for being exposed to downside consumption risk only; consumption growth risk per se is not priced.

For our main tests, we examine the fit of the proposed asset pricing model using annual returns of the size, value, reversal, profitability, and investment portfolios. These portfolios are the basis for the most frequently used pricing factors (e.g., HML, SMB, CMA, and RMW in Fama and French $(1993,2015))$. The results are striking. The disappointment indicator can fit the cross-sections of expected returns at least as accurately as the Fama-French three-factor model (FF3), and its performance is comparable to the Fama-French five-factor specification (FF5). In particular, the cross-sectional $R^{2}$ s for our single-factor model are: $90 \%$ for the size/book-to-market portfolios, $88 \%$ for the size/profitability portfolios, $74 \%$ for the size/investment portfolios, and $87 \%$ for the long-term reversal portfolios. The corresponding $R^{2}$ s for the Fama-French three-factor model are 85\%, 80\%, 73\%, and 93\%, while for the five-factor specification, the $R^{2}$ s are $82 \%, 88 \%, 81 \%$, and $97 \%$, respectively. A fortiori, our single-factor model can also explain the premia of the five Fama and French (2015) factors.

Our tests also provide insights on the plausibility of the preference parameters of consumptionbased models. Specifically, the key parameter in the proposed model is the disappointment aversion coefficient, which measures the asymmetry in investor preferences over gains and losses. Our estimates of this coefficient are around 4 at the portfolio level, implying that investors penalize losses during disappointment events 5 times more than losses during normal times. These values are very close to the one employed by Ang, Bekaert, and Liu (2005) to 
explain the historical equity premium, and yield very realistic risk-taking behavior in Rabin (2000) games (see Ang et al. (2005)).

Moreover, our estimates for the disappointment aversion coefficient remain fairly stable across subperiods, test assets, and return frequencies. To the contrary, the standard CCAPM or alternative definitions of consumption risk, such as the one introduced by Jagannathan and Wang (2007), yield quite high estimates of second-order risk aversion, rendering the representative investor implausibly risk averse over modest or large-stake gambles (see Rabin (2000)). This limitation is exacerbated with higher frequency consumption data.

Similar are the results when we alternatively consider a joint cross-section of equity, corporate bond, Treasury bond, and equity index option portfolios. At the annual frequency, the cross-sectional $R^{2}$ of our single-factor model is $72 \%$. More importantly, our model yields relatively low pricing errors for these alternative asset classes, both individually and jointly, with very similar and plausible disappointment aversion coefficient estimates. To the contrary, the Fama-French models can only fit well each of these cross-sections with factor coefficient estimates whose signs and magnitudes are strikingly inconsistent.

Next, we assess the importance of the generalized disappointment threshold. To this end, we compare the empirical fit of our single-factor model, which is derived from the generalized disappointment aversion specification of Routledge and Zin (2010), to that of a restricted version based on the original disappointment framework of Gul (1991). We find that in the sample of equity portfolios, the two models exhibit similar cross-sectional performance. In contrast, when we consider the sample of corporate bond, Treasury bond, and equity index option portfolios, the empirical fit of the generalized disappointment model is better than that of its restricted version.

We conclude our analysis by showing that the proposed model does not suffer from weak identification, and its empirical success is neither spuriously driven by the use of an indicator factor nor is particularly sensitive to the marginal characterization of some consumption growth observations as disappointing or not. 
Overall, this study contributes to various strands of the asset pricing literature. We contribute to the literature on disappointment aversion, which has considerably grown following the works of Ang et al. (2005) and Routledge and Zin (2010). ${ }^{1}$ Routledge and Zin (2010) and Bonomo, Garcia, Meddahi, and Tédongap (2011) calibrate consumption-based models with disappointment aversion to explain the equity premium but do not provide results for the cross-section of expected returns.

Ostrovnaya, Routledge, and Zin (2006) and Faragó and Tédongap (2017) conduct crosssectional tests based on disappointment aversion, but they substitute out consumption, and they propose multi-factor pricing models based on stock market returns. In contrast, our single-factor model is expressed in terms of observable consumption growth alone, and we show that the disappointment consumption indicator is sufficient to explain the cross-section of expected returns. This is particularly important because, unlike the above models, our specification provides a direct link between the macroeconomy and asset prices.

Our work is also related to Delikouras (2017), who incorporates disappointment aversion in Epstein-Zin preferences and derives a highly nonlinear SDF. To the contrary, assuming a disappointment averse but second-order risk-neutral representative investor, we introduce a much simpler SDF, which is linear in the price of disappointment risk. This innovation facilitates the estimation of our model, allowing us to conduct standard asset pricing tests using large cross-sections, and to contribute to the ongoing debate in the literature regarding the theoretical underpinnings of multi-factor models.

Our results also contribute to the consumption-based asset pricing literature. Specifically, we show that a nonlinear transformation of the consumption growth process, which derives from generalized disappointment aversion preferences, can address the empirical shortcomings of the standard consumption model. Moreover, whereas Boguth and Kuehn (2013) argue that heteroscedasticity in consumption growth substantially improves the fit of the consump-

\footnotetext{
${ }^{1}$ Choi, Fisman, Gale, and Kariv (2007) and Dahlquist, Faragó, and Tédongap (2017) examine portfolio choices, whereas Gill and Prowse (2012) focus on effort provision. Schreindorfer (2014) uses disappointment aversion to price put options.
} 
tion model, we show that our SDF, which for simplicity is derived under the assumption of homoscedasticity, still yields a very good fit for the most commonly used portfolio crosssections. Finally, the empirical success of the proposed single-factor model provides support for the theoretical argument in Breeden (1979) that premia should be proportional to covariances with a function of aggregate consumption, but we crucially show that it is downside consumption risk that is priced.

Collectively, our results question the effectiveness of the standard framework of smooth utility functions that is commonly used in consumption-based asset pricing. In contrast, we argue in favor of first-order risk aversion, and conclude that risk premia are, to a large extent, compensation for exposure to disappointment consumption risk.

\section{The Single-Factor GDA-I SDF}

In this section, we introduce our single-factor asset pricing model, termed GDA-I. Our starting point is the generalized disappointment aversion (GDA) intertemporal SDF of Routledge and Zin (2010):

$$
\begin{aligned}
& M_{t+1}^{G D A}=\beta\left(\frac{C_{t+1}}{C_{t}}\right)^{\rho-1}\left[\frac{V_{t+1}}{\mu_{t}\left(V_{t+1}\right)}\right]^{\alpha-\rho}\left[\frac{1+\theta \mathbf{1}\left\{V_{t+1} \leq \delta \mu_{t}\right\}}{1-\theta\left(\delta^{\alpha}-1\right) \mathbf{1}\{\delta>1\}+\theta \delta^{\alpha} \mathbb{E}_{t}\left[\mathbf{1}\left\{V_{t+1} \leq \delta \mu_{t}\right\}\right]}\right] \\
& \text { with } \mu_{t}\left(V_{t+1}\right)=\mathbb{E}_{t}\left[\frac{V_{t+1}^{\alpha}\left(1+\theta \mathbf{1}\left\{V_{t+1} \leq \delta \mu_{t}\right\}\right)}{1-\theta\left(\delta^{\alpha}-1\right) \mathbf{1}\{\delta>1\}+\theta \delta^{\alpha} \mathbb{E}_{t}\left[\mathbf{1}\left\{V_{t+1} \leq \delta \mu_{t}\right\}\right]}\right]^{\frac{1}{\alpha}}
\end{aligned}
$$

This SDF adjusts expected values by taking into account investor preferences over the timing, risk, and disappointment of stochastic payoffs. $\mu_{t}\left(V_{t+1}\right)$ is the GDA certainty equivalent for lifetime utility $V_{t}$, and $\mathbf{1}\left\{V_{t+1} \leq \delta \mu_{t}\right\}$ is the disappointment indicator. The parameter $\beta$ is the rate of time preference, $\rho$ determines the elasticity of intertemporal substitution (EIS $=1 /(1-\rho))$, and $\alpha$ is the second-order risk aversion parameter, which determines the piecewise concavity of lifetime utility.

The disappointment aversion (DA) coefficient $\theta$ is the novel parameter in the GDA SDF. 
This parameter determines the asymmetry in investor preferences around the disappointment threshold. When $\theta$ is positive, a $\$ 1$ loss in consumption during disappointment periods hurts approximately $1+\theta$ times more than a $\$ 1$ loss in consumption during normal times. ${ }^{2}$ When $\theta$ is 0, we obtain the standard Epstein-Zin (Epstein and Zin (1989)) framework. In the original framework of Gul (1991) and in Delikouras (2017), disappointment events take place when lifetime utility falls bellow its certainty equivalent: $\mathbf{1}\left\{V_{t+1} \leq \mu_{t}\right\}$. In this study, however, we follow the GDA framework of Routlegde and Zin (2010), where the disappointment threshold is a multiple of the certainty equivalent, i.e., $\mathbf{1}\left\{V_{t+1} \leq \delta \mu_{t}\right\}$. Thus, in the GDA model, the threshold for disappointment is also determined by the positive GDA parameter $\delta$.

According to the expression in equation (1), the GDA SDF of Routledge and Zin (2010) is a function of the observable consumption growth and the unobservable lifetime utility, because investor preferences are nonseparable across time. To substitute the unobservable lifetime utility out of the expression for the GDA SDF, we need to impose additional structure on the consumption growth process. In particular, we follow the consumption growth literature (see e.g., Mehra and Prescott (1985), Routledge and Zin (2010)), and assume that consumption growth $\left(\Delta c_{t}\right)$ is a homoscedastic $\mathrm{AR}(1)$ process with normal shocks:

$$
\Delta c_{t+1}=\mu_{c}\left(1-\phi_{c}\right)+\phi_{c} \Delta c_{t}+\sqrt{1-\phi_{c}^{2}} \sigma_{c} \epsilon_{c, t+1}
$$

The parameters $\mu_{c}, \sigma_{c}^{2}$, and $\phi_{c}$ are the unconditional mean, variance, and first-order autocorrelation for consumption growth, respectively, while $\epsilon_{c, t+1}$ are i.i.d. $N(0,1)$ shocks.

The main modeling innovation of our study is to assume that the representative investor is second-order risk-neutral with time-separable preferences, i.e., $\alpha=\rho=1$ in equation (1). In other words, we assume that the utility function of the representative investor is piecewise linear with a kink, the location of which is endogenously determined. The assumption that $\rho$ equals 1 implies that in a deterministic world, intertemporal substitution is perfectly elastic. However, in a stochastic environment with nonseparable disappointment aversion

\footnotetext{
${ }^{2}$ This behavior is consistent with a growing body of evidence documenting that disappointment risk is priced both at the individual and at the aggregate level (see Epstein and Zin (1990, 2001), Choi et al. (2007), Routledge and Zin (2010), Gill and Prowse (2012)).
} 
preferences, the effective EIS and risk aversion coefficients depend on all four preference parameters: $\alpha, \theta, \rho$, and $\delta$ (see Routledge and Zin (2010)). Thus, in a stochastic world, the assumption that $\rho$ is 1 does not necessarily imply an infinite EIS.

Moreover, it should be noted that this study examines the determination of unconditional asset premia, rather than interest rate dynamics, and hence the assumption $\rho=1$ is not particularly restrictive. In fact, the assumption $\alpha=\rho=1$ is motivated by the goal of this study, which is to show that a single-factor specification with disappointment aversion alone can sufficiently explain the cross-section of expected returns. Allowing $\alpha$ and $\rho$ to be free parameters would only increase the flexibility of our disappointment model.

Given these preferences assumptions, we introduce a very simple SDF that depends only on a disappointment consumption indicator. Specifically, in Section A1 of the Internet Appendix, we show that for $\alpha=\rho=1$, we can recast the GDA SDF of equation (1) as:

$M_{t+1}^{G D A}=\frac{\beta\left(1+\theta \mathbf{1}\left\{\Delta c_{t+1} \leq \mu_{c}\left(1-\phi_{c}\right)+\phi_{c} \Delta c_{t}+d_{2} \sqrt{1-\phi_{c}^{2}} \sigma_{c}\right\}\right)}{1-\theta(\delta-1) \mathbf{1}\{\delta>1\}+\theta \delta \mathbb{E}_{t}\left[\mathbf{1}\left\{\Delta c_{t+1} \leq \mu_{c}\left(1-\phi_{c}\right)+\phi_{c} \Delta c_{t}+d_{2} \sqrt{1-\phi_{c}^{2}} \sigma_{c}\right\}\right.}$,

where $d_{2}$ is the solution to a fixed-point problem (equation (A.14) in the Internet Appendix).

Motivated by the structural GDA SDF above and focusing on excess returns in our empirical analysis, we propose a linear SDF with respect to the price of disappointment risk, which reads up to a multiplicative scalar term as:

$$
M_{t+1}^{G D A-I}=\tilde{\theta} \mathbf{1}\left\{\Delta c_{t+1} \leq \mu_{c}\left(1-\phi_{c}\right)+\phi_{c} \Delta c_{t}+d_{2} \sqrt{1-\phi_{c}^{2}} \sigma_{c}\right\}
$$

where $\tilde{\theta}$ denotes the DA coefficient, i.e., the price of disappointment risk in this linear model. We term the above SDF as GDA-I(ndicator) for two reasons. First, it is a special case of the GDA SDF of Routledge and Zin (2010). Second, it corresponds to a single-factor model that depends only on an indicator function.

Contrary to the general GDA SDF in equation (1) and the traditional CCAPM specification, consumption growth risk per se is not priced in our GDA-I model due to the second- 
order risk neutrality assumption. Specifically, the GDA-I SDF in equation (4) indicates that risky assets should compensate investors for a single source of systematic risk, namely disappointment consumption risk, which is captured by the disappointment indicator $\mathbf{1}\{\}$. In other words, the proposed GDA-I SDF consists of a single pricing factor, the indicator of consumption growth being less than its generalized certainty equivalent $\mu_{t}^{G D A-I}\left(\Delta c_{t+1}\right)$, which is defined as

$$
\mu_{t}^{G D A-I}\left(\Delta c_{t+1}\right)=\mu_{c}\left(1-\phi_{c}\right)+\phi_{c} \Delta c_{t}+d_{2} \sqrt{1-\phi_{c}^{2}} \sigma_{c}
$$

The disappointment indicator in equation (4) is scaled by the DA parameter $\tilde{\theta}$, which captures the price of disappointment risk. The coefficient $d_{2}$ in equations $(4)$ and (5) is the disappointment threshold coefficient. In principle, this parameter is an implicit function of consumption growth moments, the GDA coefficient $\delta$, and the DA parameter $\theta$ (see equation (A.14) in the Internet Appendix). Since $\delta$ is a free parameter, to facilitate estimation and maintain the linearity of the GDA-I model with respect to the price of disappointment risk, we directly estimate $d_{2}$ via GMM.

Essentially, the GDA-I SDF in equation (4) follows a bi-modal distribution, exhibiting a switching-type behavior even though the consumption growth process does not (see Epstein and Zin (2001) for a related discussion). Testing the goodness of fit of this parsimonious single-factor SDF, we basically test whether disappointment consumption risk alone suffices to price the cross-section of expected returns. This is an important innovation relative to existing disappointment aversion models and a more challenging task relative to the GDA SDFs of Routledge and Zin (2010) and Delikouras (2017), because our preferences forego the flexibility that unrestricted second-order risk aversion and EIS parameters would allow. 


\section{A. Alternative Asset Pricing Models}

In addition to the GDA-I model, we estimate the following set of asset pricing models:

$$
\begin{aligned}
& M_{t+1}^{C C A P M}=-\tilde{\alpha} \Delta c_{t+1} \\
& M_{t+1}^{C A P M}=-b_{m} R_{m, t+1}^{x} \\
& M_{t+1}^{F F 3}=-b_{m} R_{m, t+1}^{x}-b_{s m b} R_{s m b, t+1}-b_{h m l} R_{h m l, t+1} \\
& M_{t+1}^{F F 5}=-b_{m} R_{m, t+1}^{x}-b_{s m b} R_{s m b, t+1}-b_{h m l} R_{h m l, t+1}-b_{r m w} R_{r m w, t+1}-b_{c m a} R_{c m a, t+1} \\
& M_{t+1}^{N B E R}=b_{n b e r} \mathbf{1}\{\text { more than } 4 \text { NBER recession months in year } t+1\}
\end{aligned}
$$

The discount factor in equation (6) is the linearized CCAPM with CRRA preferences. The coefficient $\tilde{\alpha}$ is the second-order risk aversion parameter that captures the price of consumption risk in the linearized CCAPM. The CCAPM represents the traditional view in consumption-based asset pricing, according to which investors are second-order risk averse but disappointment risk-neutral. The SDF $M_{t+1}^{C A P M}$ corresponds to the standard CAPM, whereas $M_{t+1}^{F F 3}$ and $M_{t+1}^{F F 5}$ correspond to the Fama and French $(1993,2015)$ three- and fivefactor models, respectively. Finally, $M_{t+1}^{N B E R}$ is the NBER discount factor, which is based on an indicator function for recessions. This indicator takes the value 1 when there are more than 4 NBER recession months in year $t+1$ and 0 otherwise. ${ }^{3}$ The parameter $b_{n b e r}$ in equation (10) is the price of NBER recession risk.

The choice of the above models is warranted by the the fact that, with the exception of the NBER model, these specifications are the workhorses of empirical asset pricing. Additionally, we use the NBER model to show that disappointment consumption events do not simply capture NBER recessions, but they rather have distinct asset pricing implications.

\footnotetext{
${ }^{3}$ Because NBER recessions are defined on a monthly basis, we create an annual NBER indicator by considering a 4-month cutoff for the number of NBER recession months in a year. We have considered alternative cutoffs for the NBER indicator. The 4-month cutoff yields the best cross-sectional fit. Based on this cutoff, the NBER recession years are 1937, 1938, 1945, 1949, 1953, 1954, 1960, 1970, 1974, 1980, 1981, 1982, 1990, 2001, 2008, and 2009.
} 


\section{Data and Estimation Methodology}

\section{A. Data}

The aim of our empirical analysis is to examine whether the GDA-I model can explain stylized facts in the cross-section of equity returns. To this end, we consider the following portfolio cross-sections: ${ }^{4}$

1. 6 and 25 portfolios sorted on size/book-to-market (SIZE/BM). These portfolios capture the size and value premia, which are reflected in the SMB and HML factors of the Fama and French (1993) three-factor model. ${ }^{5}$

2. 25 portfolios sorted on size/operating profitability (SIZE/OP). These portfolios capture the profitability premia, which are reflected in the RMW factor of the Fama and French (2015) five-factor model.

3. 25 portfolios sorted on size/investment (SIZE/INV). These portfolios capture the investment premia, which are reflected in the CMA factor of the Fama and French (2015) five-factor model.

4. 10 portfolios sorted on long-term reversal (LTR). These portfolios capture the long-term reversal premium documented in Jegadeesh and Titman (1993).

We use the above sets of portfolios for two reasons. First, these sets of equity portfolios constitute the basis for a number of return-generated factors that are commonly used in the empirical asset pricing literature, such as the SMB, HML, CMA, and RMW factors in Fama and French (1993, 2015). Second, as shown in Harvey et al. (2015) and Hou et al. (2016), the above portfolios are also the basis for a wide range of well-established patterns in the

\footnotetext{
${ }^{4}$ In Section A12 of the Internet Appendix, we report additional results at the stock level.

${ }^{5}$ In Section A8 of the Internet Appendix, we also consider 100 size/book-to-market portfolios and 10 earnings-to-price portfolios as alternative value-related cross-sections.
} 
cross-section of equity returns. Details on the construction of these portfolios can be found on Kenneth French's website, while their summary statistics are shown in Table 1.

Our benchmark analysis employs annual data, whereas the Internet Appendix contains the corresponding results using monthly and quarterly portfolio returns. Our main results for the SIZE/BM and LTR portfolios span the post-Great Depression period, 1933-2012, ${ }^{6}$ whereas profitability and investment portfolios are available since 1964 .

For external validation, we additionally examine whether the GDA-I model can explain the level and cross-sectional variation of bond and equity index option premia. To this end, we use 5 corporate bond portfolios sorted on the basis of their credit ratings, ${ }^{7} 6$ Treasury bond portfolios sorted on maturity, ${ }^{8}$ and 6 equity index option portfolios. ${ }^{9}$ The Treasury bond portfolios are available since 1952, the corporate bond portfolios are available for the period 1976-2009, and the option portfolios are available for the period 1987-2011.

GDA-I is a consumption-based model. To construct the per-capita aggregate consumption series, we use personal consumption expenditures (PCE) and PCE price index data from BEA. ${ }^{10}$ Aggregate consumption is defined as services plus nondurables. Each component of aggregate consumption is deflated by its corresponding PCE price index (base year is 2009). Population data are from the U.S. Census Bureau and recession dates are from the NBER. In matching consumption growth with asset returns, we follow the "beginning-of-period" convention as in Campbell (2003), Yogo (2006), and Savov (2011), because beginning-of-period consumption growth is better aligned with asset returns.

\footnotetext{
${ }^{6}$ In Section A2 of the Internet Appendix, we alternatively examine the entire sample period for which aggregate consumption data are available from BEA, i.e., 1930-2012, including Great Depression years.

${ }^{7}$ These corporate bond portfolios have been constructed by Nozawa (2012), and they are available from Michael Weber's website: http://faculty.chicagobooth.edu/michael.weber/.

${ }^{8}$ These are the Fama Maturity Portfolios provided by CRSP.

${ }^{9}$ In particular, we use the 30-day, put and call S\&P 500 index option portfolios with moneyness levels of 90, 100, and 110\%, respectively, of Constantinides, Jackwerth, and Savov (2013). These option portfolio returns are available from Alexi Savov's website: http://pages.stern.nyu.edu/ asavov/alexisavov/.

${ }^{10}$ Monthly consumption data used in Section A5 of the Internet Appendix are available since 1959. Quarterly consumption data used in Section A6 of the Internet Appendix are available since 1947.
} 


\section{B. Estimation Methodology}

We test the competing asset pricing models in equations (6)-(10) using first-stage GMM (Hansen and Singleton (1982)) with an identity weighting matrix for the following system of Euler equations: ${ }^{11}$

$$
\mathbb{E}\left[\left(R_{i, t}-R_{1 y, t}\right)\left(1-\mathbb{E}\left[M_{t}\right]+M_{t}\right)\right]=0, \text { for } i=1, . ., n,
$$

where $R_{1 y, t}$ is the one-year interest rate and $n$ is the number of test assets. Consistent with Burnside's (2011) generic SDF representation for linear factor models, we augment the SDFs specified in equations (4) and (6)-(10) by $1-\mathbb{E}\left[M_{t}\right]$ to rule out a zero solution for risk prices since we are testing linear models on excess returns. Also, using the definition of covariance, we obtain the following equivalent expression for expected portfolio premia:

$$
\mathbb{E}\left[R_{i, t}-R_{1 y, t}\right]=-\operatorname{cov}\left(R_{i, t}-R_{1 y, t}, M_{t}\right) \text { for } i=1, . ., n
$$

Based on the above, this GMM setup is equivalent to running a cross-sectional regression of portfolio premia on covariances imposing a zero intercept. However, the critical advantage of the GMM specification is that it automatically corrects standard errors for the fact that covariances of excess returns with the SDF need also be estimated.

To test the performance of the GDA-I model in equation (4), we need to identify the set of disappointment consumption events, and hence we need to specify the values for the mean $\left(\mu_{c}\right)$, variance $\left(\sigma_{c}^{2}\right)$, and autocorrelation $\left(\phi_{c}\right)$ of consumption growth. To this end, for the GDA-I model alone, we minimize the following augmented GMM system that fits the empirical consumption growth moments jointly with the unconditional Euler equations for excess portfolio returns:

\footnotetext{
${ }^{11}$ In Section A3 of the Internet Appendix, we alternatively estimate the various asset pricing models using a two-stage GMM approach.
} 


$$
\left[\begin{array}{l}
\mathbb{E}\left[\Delta c_{t}\right]-\mu_{c} \\
\mathbb{E}\left[\Delta c_{t}^{2}\right]-\mu_{c}^{2}-\sigma_{c}^{2} \\
\mathbb{E}\left[\Delta c_{t} \Delta c_{t-1}\right]-\mu_{c}^{2}-\phi_{c} \sigma_{c}^{2} \\
\mathbb{E}\left[\left(R_{i, t}-R_{1 y, t}\right)\left(1-\mathbb{E}\left[M_{t}^{G D A-I}\right]+M_{t}^{G D A-I}\right)\right] \text { for } i=1, . ., n
\end{array}\right]=\mathbf{0}
$$

In minimizing the above GMM system, we use a diagonal weighting matrix in which the first three diagonal elements are very large numbers $\left(10^{8}\right)$, and the remaining diagonal elements are 1 . There are two reasons for overweighting the moment conditions for consumption growth. First, these moment conditions have a different scale from the ones for portfolio returns. For example, the annual return for the SIZE1/BM5 portfolio (= 27\%) is much larger than the sample autocovariance of the annual consumption growth $(=0.005 \%)$. Therefore, these consumption growth moments need to be weighted accordingly. Second, by overweighting the consumption growth moments, we are not allowing the estimation procedure to fit portfolio premia at the expense of errors in the consumption growth process (e.g., inflating the variability or the persistence of consumption growth).

We assess the overall model fit using the $\chi^{2}$-test (Hansen (1982)), the cross-sectional $R^{2}$, and the cross-sectional root mean square error $(R M S E)$. The magnitude of the $R M S E$ for each cross-section should be compared with the corresponding average portfolio premia reported in Table 1. Finally, it should be noted that the critique in Lewellen, Nagel, and Shanken (2010) regarding the mechanical fit of asset pricing models due to the factor structure of certain cross-sections of portfolios is less relevant for the GDA-I SDF because it is a single-factor model. 


\section{Results}

In our benchmark analysis, we estimate the various asset pricing models using annual returns for the $25 \mathrm{SIZE} / \mathrm{BM}, 25 \mathrm{SIZE} / \mathrm{OP}, 25 \mathrm{SIZE} / \mathrm{INV}$, and $10 \mathrm{LTR}$ portfolios, in turn. The results for equal-weighted portfolios are reported in Table 2, whereas the corresponding results for value-weighted portfolios are reported in Table 3.

\section{A. Model Fit}

The results in Table 2 for equal-weighted portfolios show that the GDA-I model achieves a very good fit in absolute terms, with $R^{2}$ being as high as $90 \%$ in the cross-section of the 25 SIZE/BM portfolios. The goodness of fit is also high across the 25 SIZE/OP, 25 SIZE/INV, and 10 LTR portfolios $\left(R^{2} \mathrm{~s}=88 \%, 74 \%\right.$, and $87 \%$, respectively). Additionally, the GDA-I model yields low RMSEs. This success is particularly notable for the $25 \mathrm{SIZE} / \mathrm{BM}$ and the 25 SIZE/OP portfolios, given the substantial cross-sectional dispersion in the sample premia of these portfolios. Finally, on the basis of the $\chi^{2}$-test of overidentifying restrictions, the GDA-I model cannot be formally rejected in the examined sets of portfolios.

The empirical success of the GDA-I model is also illustrated in Figure 1, which plots sample portfolio premia versus fitted expected excess returns for all models. These scatterplots show that the GDA-I model can successfully align fitted with sample premia across all portfolio sorts.

The goodness of fit of the GDA-I model is even more striking when assessed relatively to the alternative, commonly used asset pricing models. The GDA-I model outperforms the CCAPM in terms of goodness of fit. This outperformance is more pronounced among the 25 SIZE/INV portfolios, where the CCAPM performs very poorly. This is also evident from Panel $\mathrm{C}$ of Figure 1. It should be also mentioned that the CCAPM is formally rejected by the $\chi^{2}$-test in all but one of the portfolio sets considered. Equally importantly, the GDAI model outperforms the CAPM, which yields much lower $R^{2}$ s and much higher $R M S E \mathrm{~s}$ 
across the board. Interestingly, the CAPM not only fails badly to price the 25 SIZE/INV and the 25 SIZE/OP portfolios, but also yields a twice as high $R M S E$ as the GDA-I model for the 25 SIZE/BM portfolios. Moreover, the CAPM is rejected by the $\chi^{2}$-test for all sets of portfolios considered.

A challenging benchmark for the GDA-I model is the Fama-French three-factor model. Despite the fact that our model utilizes a single macroeconomic indicator variable, its goodness of fit is very similar to that of the Fama-French model. In fact, in the cross-section of the 25 SIZE/BM portfolios, from which the SMB and HML factors are constructed, the GDA-I model yields a higher $R^{2}$ and a lower $R M S E$ relative to this model. The same is true for the $25 \mathrm{SIZE} / \mathrm{INV}$ and the $25 \mathrm{SIZE} / \mathrm{OP}$ portfolios. On the other hand, the threefactor model outperforms the GDA-I model in the cross-section of the 10 LTR portfolios, where it achieves an almost perfect fit. The overall relative parity in terms of goodness of fit among these two models is illustrated in Figure 1. Finally, it should be mentioned that the Fama-French model is rejected by the $\chi^{2}$-test for all sets of portfolios considered.

The GDA-I model also compares very well with respect to the Fama-French five-factor model. The corresponding estimation results in Table 2 show that the five-factor model outperforms the GDA-I model across the 25 SIZE/INV portfolios, but it underperforms our model across the $25 \mathrm{SIZE} / \mathrm{BM}$ portfolios. Both models achieve an equally good fit across the 25 SIZE/OP portfolios.

To show that the empirical success of the GDA-I model does not derive from naively mimicking recession periods, we also compare it with the NBER model. In fact, we find that a simple NBER recession indicator cannot price at all the SIZE/INV and SIZE/OP portfolios, since it yields very high $R M S E \mathrm{~s}$ and very low $R^{2} \mathrm{~s}$. The very poor performance of the NBER model can be visualized by the scatterplots in the fourth column of Figure 1. These results imply that NBER recessions are not particularly important for risk premia.

Overall, the performance of the GDA-I model indicates that investors are sensitive to disappointment consumption years and require a higher premium for holding assets that 
perform badly during these years. In fact, the results in Table 2 suggest that downside consumption risk, as measured by disappointment events in consumption growth, can explain both the level and the cross-sectional variation in portfolio premia. Hence, we argue that to a large extent, SIZE, BM, OP, INV, and LTR premia are compensation for exposure to downside consumption risk.

Contrary to a number of previous studies that propose mispricing as an explanation for equity premia, our results support a risk-based rationalization for the cross-section of stock returns. Specifically, the successful performance of the GDA-I model in the SIZE/BM cross-section challenges the conclusions in Lakonishok et al. (1994), who suggest that bookto-market effects are a result of investor overreaction to past firm performance. Lakonishok et al. (1994) and DeBondt and Thaler (1985) propose an overreaction explanation for the long-term reversal premium as well. Yet, the reported results for the LTR portfolios in Table 2 indicate that disappointment risk can explain the long-term reversal puzzle too.

\section{B. Prices of Risk and Disappointment Threshold Coefficient}

In addition to model fit, Table 2 reports the estimated prices of risk across the various models and portfolio sorts considered. For the GDA-I and CCAPM specifications, the prices of risk have a structural interpretation and can be directly mapped into preference parame-

ters. Specifically, the price of risk for the GDA-I model is the DA coefficient $\tilde{\theta}$ from equation (4), while the price of risk for the CCAPM is the second-order risk aversion parameter $\tilde{\alpha}$ from equation (6). Hence, we can also assess the plausibility of these two models by examining their implied preference parameters.

Regarding the CCAPM, the estimated risk aversion coefficients reported in Table 2 range from 57 for the SIZE/BM portfolios to 91 for the SIZE/INV portfolios. These magnitudes are consistent with the ones reported in Mehra and Prescott (1985), Cochrane (2001), and Savov (2011), and reflect the equity premium puzzle. In other words, the CCAPM requires extremely large risk aversion parameters to match equity premia. Echoing Rabin (2000), 
accepting such a high degree of concavity in the representative investor's utility function is equivalent to accepting that this investor would paradoxically reject even extremely favorable larger-stake gambles, rendering her implausibly risk averse.

On the other hand, the estimated DA coefficients reported in Table 2 range from 3.4 for the SIZE/INV portfolios to 4.3 for the LTR portfolios and they remain fairly stable across the examined cross-sections. This range of values for the DA coefficient is very close to the value required by Ang et al. (2005) to explain the historical equity premium, and implies a very reasonable risk-taking behavior in Rabin (2000) games (see Ang et al. (2005)). It should be also noted that the estimated factor coefficients reported in Table 2 reveal an important limitation of the Fama-French models. These multi-factor models achieve relatively low RMSEs in each set of test assets at the expense of strikingly different factor coefficient estimates across these cross-sections, hindering their interpretation in a theoretically consistent fashion.

Finally, Table 2 also reports estimates for the coefficient $d_{2}$ in each cross-section. According to equation (5), the parameter $d_{2}$ characterizes the threshold for disappointment in terms of standard deviations away from the conditional mean of consumption growth. For example, we find that for the SIZE/BM (LTR) portfolios in the full sample period, disappointment consumption events occur when realized consumption growth is $0.77(0.75)$ standard deviations below its conditional mean. The threshold is somewhat higher for the SIZE/INV and SIZE/OP portfolios in the post-1964 period, but the corresponding estimates for $d_{2}$ are not directly comparable since the consumption growth moments are also different in this subperiod.

In particular, the estimates of the annual consumption growth moments for the period 1933-2012 are $2.17 \%$ for average consumption growth, $0.024 \%$ for consumption growth variance, and $0.005 \%$ for consumption growth autocovariance. For the period 1964-2012, the corresponding estimates are $1.94 \%, 0.016 \%$, and $0.010 \%$, respectively. 


\section{Value-Weighted Portfolios}

Following Liu et al. (2009), the previous empirical tests were based on equal-weighted portfolio returns because they exhibit more pronounced cross-sectional variation. For robustness, in this section, we alternatively use value-weighted portfolio returns. Table 3 and Figure 2 report the corresponding results for the various asset pricing models at the annual frequency.

Comparing the results reported in Table 3 and Figure 2 for value-weighted returns with the ones reported in Table 2 and Figure 1 for equal-weighted returns, we can make the following observations. First, the GDA-I model maintains its very good fit both in absolute and in relative terms, yielding low pricing errors across the four sets of portfolios used in our benchmark analysis. The GDA-I model outperforms the competing single-factor models, and its goodness of fit is comparable to that of the multi-factor Fama-French models.

Second, the DA coefficients estimated from the GDA-I model are very close to the ones derived using equal-weighted portfolios, implying again a very reasonable risk-taking behavior for the representative investor. The same is true for the corresponding estimates of the disappointment threshold coefficient. Moreover, the second-order risk aversion coefficients estimated from the CCAPM are again implausibly high.

Third, the goodness of fit that the multi-factor Fama-French models achieve comes at the expense of strikingly different factor coefficient estimates, both across portfolio cross-sections and across weighting schemes. In sum, the results presented in Table 3 and Figure 2 confirm that the pricing ability of the proposed single-factor GDA-I model is not sensitive to the choice of the portfolio weighting scheme.

\section{Additional Results}

In the Internet Appendix, we repeat our benchmark analysis following a series of alternative empirical approaches using: (i) the full sample period for which aggregate consumption 
data are available from BEA, i.e., 1930-2012 (Section A2), (ii) a two-stage GMM estimation procedure (Section A3), (iii) a recursive GMM estimation approach with expanding time windows (Section A4), (iv) monthly portfolio returns (Section A5), (v) quarterly portfolio returns (Section A6), (vi) a joint cross-section combining all equity portfolios (Section A7), and (vii) alternative value-related cross-sections (100 size/book-to-market and 10 earningsto-price portfolios in Section A8). The results from these alternative empirical approaches are similar to the ones reported in Tables 2 and 3. In particular, the GDA-I model yields a very good fit across portfolio sorts, both in absolute and in relative terms, while the disappointment aversion coefficient estimates are rather stable and they imply reasonable risk-taking behavior. ${ }^{12}$

Another important point regarding the empirical tests in Tables 2 and 3 is that in fitting the three return-based SDFs (CAPM, FF3, FF4), the prices of risk are free parameters estimated by GMM. This approach guarantees maximum flexibility for these models, whose prices of risk vary substantially across the different test assets. However, the factors in these SDFs are themselves excess returns of traded assets. Thus, in principle, the prices of risk in these models should be constrained by the expected returns of the factors, as suggested by Cochrane (2001, p. 107). Therefore, in Section A9 of the Internet Appendix, we repeat our benchmark analysis imposing price-of-risk restrictions on the return-based SDFs. These restrictions are derived from the additional condition that the return-based models should be able to perfectly fit the corresponding return-based factors.

According to the results in Section A9 of the Internet Appendix, when we require the return-based SDFs to perfectly price their factors, their goodness of fit considerably deteriorates. For instance, the $R^{2}$ s of the restricted FF5 model in the four portfolio sorts of our benchmark analysis become $72 \%, 62 \%, 66 \%$, and $40 \%$, respectively. These $R^{2}$ s are substantially worse than those of the single-factor GDA-I model reported in Table 2. This is

\footnotetext{
${ }^{12}$ We have also repeated our benchmark analysis for the post-1945 period. The explanatory power of the GDA-I model remains strong during this sample period. In particular, the $R^{2} \mathrm{~s}$ for the GDA-I model with respect to the 25 SIZE/BM and 10 LTR portfolios are $86 \%$ and $87 \%$, respectively. The corresponding $R^{2} \mathrm{~s}$ for the CCAPM are $63 \%$ and $46 \%$, and for the FF3 specification are $75 \%$ and $94 \%$.
} 
an alternative way of interpreting the instability of the prices of risk that the return-based SDFs exhibit across the various test assets. In contrast, the single-factor GDA-I model can explain expected returns with a price of disappointment risk that remains stable across the alternative cross-sections.

\section{Alternative Asset Classes}

Up to this point, we have examined an extensive set of equity portfolio sorts. However, the proposed consumption-based GDA-I model should be able to price all assets in the economy. To this end, this section examines the pricing ability of the GDA-I model with respect to other asset classes. In particular, we consider the 5 corporate bond portfolios of Nozawa (2012) that have been constructed on the basis of bonds' credit ratings, the 6 Fama maturity-sorted Treasury bond portfolios, and the 630 -day, put and call S\&P 500 index option portfolios, with moneyness levels of 90, 100, and 110\%, respectively, of Constantinides et al. (2013).

First, we estimate the GDA-I and the competing pricing models for each of these three sets of portfolios. To ensure that the estimated model coefficients simultaneously explain the equity premium apart from fitting the corresponding cross-section, we also add the equity market portfolio to each of these three sets of portfolios. Second, along the lines of Lettau et al. (2014), we test the pricing ability of the various models using a joint cross-section of equity, corporate bond, Treasury bond, and equity index option portfolios. In this way, we examine whether the same risk price(s) can simultaneously explain the cross-sectional premia that different asset classes yield.

Corporate bond, Treasury bond, and equity index option portfolio returns are jointly available only for the period 1987-2009. Due to this short sample period, and to ensure that each of the asset classes is evenly represented in the joint cross-section, the equity portfolios we use are the 6 Fama-French SIZE/BM portfolios. We present results for annual 
portfolio returns of the alternative test assets in Table 4, whereas Section A10 in the Internet Appendix contains the corresponding results using monthly portfolio returns.

Panel A of Table 4 presents the results for the corporate bond portfolios. We find that the GDA-I model can almost perfectly explain the cross-section of their premia. This goodness of fit can be visualized in Panel A of Figure 3. In fact, the corporate bonds with the highest credit spreads are the most exposed ones to disappointment consumption risk. Hence, the high premia they yield can be regarded as compensation for this aspect of risk. Interestingly, the estimated price of disappointment risk (estimate $=3.7$ ) is very similar in magnitude to the ones derived from equity portfolio sorts. In relative terms, the GDA-I model outperforms the competing single-factor models, and the CCAPM still implies an implausibly high risk aversion coefficient. Equally importantly, the multi-factor Fama-French models can only fit this cross-section through extremely large or even negative factor coefficient estimates, which are at odds with the corresponding estimates derived from equity portfolio sorts.

The results for the Treasury bond portfolios (Panel B in Table 4 and in Figure 3) are very similar to the ones for the corporate bond portfolios, even though the cross-sectional dispersion of Treasury bond premia is much less pronounced than the one of the corporate bond premia.

Panel C of Table 4 presents the corresponding results for the equity index option portfolios. The GDA-I model achieves again a very good fit, both in absolute and in relative terms. The DA coefficient estimate is also very similar in magnitude to the ones derived from equity portfolios as well as from corporate and Treasury bond portfolios (estimate $=4.4$ ). Panel C of Figure 3 shows that the pricing errors for most of these option portfolios are low. Most importantly, the GDA-I model goes a long way in explaining the very high premium earned by the 30-day deep out-of-the-money (OTM) equity index put option portfolio, which has hitherto proven notoriously difficult to rationalize (see the discussion in Constantinides et al. $(2013)) \cdot{ }^{13}$

\footnotetext{
${ }^{13}$ Recall that, according to the definition of Constantinides et al. (2013), put portfolios have a short position in puts.
} 
Contributing to this strand of the literature, we find that this 30-day OTM index put option portfolio is severely exposed to disappointment consumption risk, explaining why it commands a very high risk premium. A natural interpretation of this result is that deep OTM index put options provide insurance against disappointment consumption events, so a sufficiently disappointment averse investor is willing to pay a high premium to the counterparty who provides this insurance (see Schreindorfer (2014) for a similar argument). In relative terms, the GDA-I model clearly outperforms the competing single-factor models. Again, the Fama-French models can only fit this cross-section through factor coefficient estimates whose signs and magnitudes are strikingly inconsistent.

Finally, Panel D of Table 4 presents the model estimates for the joint cross-section of equity, corporate bond, Treasury bond, and equity index option portfolios. Interestingly, we find that the GDA-I model can correctly price this joint cross-section $\left(R^{2}=72 \%\right)$, yielding the best fit across the competing models (see also Panel D of Figure 3). In fact, the three-factor Fama-French model performs poorly because it cannot sufficiently explain these different asset classes with the same set of factor coefficient estimates. Even worse, the fivefactor Fama-French model yields predominantly negative factor risk prices. To the contrary, the GDA-I model achieves a very good fit with a DA coefficient estimate that is very similar to the ones derived from the previously examined cross-sections (estimate $=4.1$ ), and implies a very reasonable risk-taking behavior. In conclusion, the notable pricing ability of the GDA-I model, and the stability of the DA coefficient estimates across different asset classes and subperiods, can be regarded as an external validation of our benchmark analysis.

In sum, we find that the GDA-I model clearly outperforms the competing single-factor models, whereas the multi-factor Fama-French models only achieve a good fit at the expense of extreme factor coefficient estimates. Further, the DA coefficient estimates are remarkably stable across the different asset classes, and they are consistent with the estimates we derived from the equity portfolio cross-sections. 


\section{The DA-I Model with $\delta=1$}

Our single-factor model has been developed under the GDA framework of Routledge and Zin (2010), where the disappointment threshold is a multiple of the certainty equivalent $\left(\mathbf{1}\left\{V_{t+1} \leq \delta \mu_{t}\right\}\right.$ in equation (1)), and it is determined by the GDA parameter $\delta$. In the special case where $\delta$ is restricted to be equal to 1 , the GDA framework becomes equivalent to the original DA framework of Gul (1991), where the disappointment threshold is equal to the certainty equivalent $\left(\mathbf{1}\left\{V_{t+1} \leq \mu_{t}\right\}\right)$.

To assess the importance of $\delta$ being a free parameter in the GDA framework, this section examines a restricted version of the GDA-I SDF, setting $\delta$ equal to 1 . We term the restricted disappointment model as the DA-I SDF. The specification of the DA-I model and the empirical methodology used to estimate it are identical to those for the GDA-I model in equations (4) and (13). The key difference is that in the DA-I model, the corresponding disappointment

threshold $d_{2}^{D A-I}$ in equations (4) and (5) cannot be estimated as a free parameter. Instead, $d_{2}^{D A-I}$ is an implicit non-linear function of the consumption growth moments and the DA parameter (see equation (A.15) in the Internet Appendix). Hence, to compute $d_{2}^{D A-I}$ in the DA-I model, one needs to solve the corresponding fixed-point problem while estimating the unknown parameters $\left(\mu_{c}, \phi_{c}, \sigma_{c}^{2}\right.$, and $\left.\tilde{\theta}\right)$.

Estimation results for the DA-I model are reported in Table 5. Panel A shows the results for the equity portfolio cross-sections (SIZE/BM, SIZE/OP, SIZE/INV, LTR). We find that the DA coefficient estimates from the DA-I SDF are similar, albeit slightly lower, to the corresponding estimates reported in Table 2 for the GDA-I SDF. In addition, the threshold coefficient estimates $d_{2}^{D A-I}$ we back out from the DA-I model are typically lower than the ones directly estimated from the GDA-I specification, leading to a larger number of disappointment consumption events. For instance, in the cross-section of the SIZE/BM portfolios, we get 20 disappointment consumption years from the DA-I model, whereas the GDA-I model yields only 13 such events (see Section VII below). Finally, in terms of model 
fit, the results in Panel A of Table 5 show that when the test assets are equity portfolios, the empirical fit of the DA-I SDF is very similar to the fit of our benchmark GDA-I SDF.

On the other hand, the estimation results for the alternative asset classes (corporate bond, Treasury bond, and equity index option portfolios) reported in Panel B of Table 5 indicate that, overall, the DA-I SDF performs worse than the GDA-I SDF. Moreover, the corresponding DA coefficient estimates from the DA-I model are typically lower than the ones reported in Table 4 for the GDA-I model. Similarly, the threshold coefficient values $d_{2}^{D A-I}$ we back out from the DA-I specification are mostly lower than the corresponding ones estimated from the GDA-I framework.

The fact that the empirical fit of the DA-I model in the sample of equity portfolios is very similar to that of the GDA-I model leads to two important conclusions. First, the goodness of fit of the disappointment model in the equities sample is not particularly sensitive to small variations in the threshold coefficient. This finding is consistent with the sensitivity analysis we carry out in Section VIII below. Second, as suggested by Routledge and Zin (2010), the identification of the GDA parameter $\delta$ is rather challenging. In other words, one cannot confidently argue whether $\delta$ is 1 or not solely on the basis of comparing the cross-sectional fit of the GDA-I and DA-I models.

Based on the above discussion, we consider the benchmark GDA-I model preferable to the DA-I model for three reasons. First, from a theoretical point of view, the flexibility of the GDA framework has been shown to be important in capturing a series of stylized facts in asset pricing (see Routledge and Zin (2010) and Bonomo et al. (2011)). Given the challenging identification of $\delta$, there is no obvious benefit in restricting it to be exactly equal to 1 . Second, from an empirical point of view, allowing $\delta$ to be a free parameter permits the estimation of the disappointment threshold coefficient $d_{2}$ as a free parameter, and hence enables the GDA-I model to maintain its linearity with respect to the price of disappointment risk. This feature substantially facilitates its estimation. Last, the crosssectional fit of the benchmark GDA-I SDF is overall better than that of the restricted DA-I 
specification, particularly for the alternative asset classes.

\section{Disappointment Events and High Marginal Util- ity States}

\section{A. Disappointment Events and their Characteristics}

A successful consumption-based asset pricing model needs to accurately map "bad economic times" to states of high marginal utility for the representative investor. To this end, we examine how some key economic and financial variables behave during the disappointment consumption years extracted from the cross-section of the $25 \mathrm{SIZE} / \mathrm{BM}$ portfolios (see Table 2). In particular, these disappointment years occurred in 1937, 1946, 1948, 1956, 1973, 1979-80, 1990, 1999, 2007-08, and 2011-12, and they are illustrated in Figure 4. Table 6 reports the average values of these variables in the full sample period as well as during disappointment years. Moreover, to highlight that the identified disappointment events do not simply capture recession periods, we also report the average values of these variables during NBER recession years.

With respect to stock market performance, we find that during disappointment consumption years the market premium is negative, the size premium is highly negative, and the value premium is quite low relative to its full sample average. These effects are much less pronounced when we split the sample on the basis of NBER recession years, indicating that the stock market leads NBER recessions and the disappointment indicator is successful in capturing this behavior. For instance, the HML premium during NBER recessions $(8.02 \%)$ is marginally different to the HML premium during non-recession years $(9.28 \%)$.

In contrast, the HML premium during disappointment years is much lower than during non-disappointment periods (4.23\% vs. $9.95 \%)$.

Disappointment years are associated with a lower average term spread, supporting the 
argument that the disappointment indicator can be considered as a recession leading indicator. Verifying that disappointment years are "bad times" indeed, real consumption growth is almost zero, and the corresponding earnings growth rate is less than a third of its full sample average. Confirming that consumption is low during these years, the $C A Y$ variable of Lettau and Ludvigson (2001) takes a negative average value and consumer confidence is dramatically reduced. On the other hand, we do not find disappointment years to be associated with a particularly negative market sentiment level, once this is orthogonalized with respect to macroeconomic conditions. Interestingly, net equity expansion is also very low during disappointment years, indicating that corporations anticipate the economic slowdown. Further, we find that disappointment consumption years are also associated with a high and increasing inflation rate. Finally, supporting the argument that the disappointment indicator anticipates rather than coincides with recessions, we find that these years are followed by, but do not coincide with, a higher and increasing unemployment rate.

\section{B. Expected Returns According to the GDA-I Model}

To explain the superior performance of the GDA-I model relative to the traditional CCAPM framework, we consider the expression for risk premia in equation (12). The poor performance of the CCAPM, especially at the monthly and quarterly frequencies (see Sections A5 and A6 in the Internet Appendix), is due to the inability of aggregate consumption growth to align asset returns with marginal utility. In contrast, the GDA-I factor is a nonlinear transformation of the consumption growth process, for which periods of low returns are aligned with periods of high marginal utility (disappointment consumption events).

More specifically, the GDA-I SDF in equation (4) implies that asset premia should be linearly related to their expected losses during disappointment consumption events. In particular, substituting equation (4) into equation (12), we get:

$$
\mathbb{E}\left[R_{i, t}-R_{1 y, t}\right]=-\frac{\tilde{\theta}}{1-\tilde{\theta} \mathbb{E}\left[\mathbf{1}_{t}\right]} \mathbb{E}\left[\mathbf{1}_{t}\left(R_{i, t}-R_{1 y, t}\right)\right]=-\frac{\tilde{\theta} \mathbb{E}\left[\mathbf{1}_{t}\right]}{1-\tilde{\theta} \mathbb{E}\left[\mathbf{1}_{t}\right]} \mathbb{E}\left[\left(R_{i, t}-R_{1 y, t}\right) \mid \mathbf{1}_{t}=1\right],
$$


where $\mathbf{1}_{t}$ is the disappointment indicator. By correctly identifying disappointment consumption events, the GDA-I model is able to align the full sample premia of risky assets with the average losses they incur during these events. To this end, Delikouras (2017) shows that the location of the reference point for gains and losses, i.e., the certainty equivalent of consumption growth, is crucial for this successful alignment.

Confirming these arguments, Figure 5 plots the full sample annual premia of the 25 SIZE/BM portfolios versus their full sample disappointment betas. These betas are estimated from a model where the only regressor is the disappointment indicator (GDA-I factor) extracted from the cross-section of the 25 SIZE/BM portfolios in Table 2. In fact, Figure 5 shows that portfolio premia are almost perfectly aligned with their disappointment betas $\left(R^{2}=90.1 \%\right)$. In other words, the more sensitive portfolio returns are to the occurrence of a disappointment event (i.e., the greater its losses are during this period), the higher the premium that this portfolio yields.

\section{The GDA-I Model and the Fama-French Factor Premia}

The results reported in Section IV show that the proposed GDA-I model can fit the premia of the size, value, profitability, and investment portfolio cross-sections as accurately as the multi-factor Fama-French models. This striking finding implies that the GDA-I SDF is a single-factor, consumption-based equivalent representation of the Fama-French multifactor SDFs. If this holds true, then the GDA-I model should be also able to explain the premia that the five Fama and French (2015) factors yield.

To examine the validity of this conjecture, Figure 6 plots the full sample premia of the market, SMB, HML, RMW, and CMA factors versus their disappointment betas. Again, these betas are estimated from a model where the only regressor is the disappointment indicator (GDA-I factor) extracted from the cross-section of the 25 SIZE/BM portfolios in Table 2. In line with our conjecture, we find that the factor premia are well-aligned with their GDA-I betas $\left(R^{2}=76 \%\right)$. Moreover, the slope of the linear relationship between the 
factor premia and their GDA-I betas implies a DA coefficient of 4.2, which is very close to the corresponding estimates from the portfolio cross-sections (see Table 2). These results point to the conclusion that the premia that the Fama and French (2015) factors yield reflect compensation for exposure to disappointment consumption risk.

\section{Identification and Placebo Tests}

\section{A. Identification Tests for GDA-I Betas}

Burnside (2011) and Bryzgalova (2015) convincingly show that if asset returns are weakly correlated with the candidate pricing factor, then the corresponding risk premium may be weakly identified, leading to spurious inference. To address the potential concern that the proposed GDA-I model may suffer from weak identification, we conduct a series of Wald tests regarding the joint significance and the cross-sectional dispersion of the GDA-I betas.

To this end, we jointly estimate GDA-I betas utilizing a system of seemingly unrelated regressions (SUR) of the $25 \mathrm{SIZE} / \mathrm{BM}$ portfolio excess returns as well as the market portfolio excess return on the disappointment indicator (GDA-I factor), which has been extracted from the cross-section of the 25 SIZE/BM portfolios in Table 2. The point estimates of GDA-I betas for these 25 portfolios are illustrated in Figure 5. First, we test the null hypothesis that these 25 GDA-I betas are jointly equal to zero $\left(H_{0}: \widehat{\beta}_{i}^{G D A-I}=0, \forall i\right)$. Second, we test whether the 25 GDA-I betas are jointly equal to the GDA-I beta of the market portfolio $\left(H_{0}: \widehat{\beta}_{i}^{G D A-I}=\widehat{\beta}_{m}^{G D A-I}, \forall i\right)$. Third, we test whether the 25 GDA-I betas are jointly equal to their average estimate $\left(H_{0}: \widehat{\beta}_{i}^{G D A-I}=\overline{\widehat{\beta}}^{G D A-I}, \forall i\right)$. Finally, we test whether the GDA-I beta of the small/value portfolio, which yields the highest premium (see Table 1), is equal to that of the big/growth portfolio, which yields the lowest premium $\left(H_{0}: \widehat{\beta}_{S 1 B 5}^{G D A-I}=\widehat{\beta}_{S 5 B 1}^{G D A-I}\right)$.

The Wald statistics reported in Table 7 indicate that we can reject each of these four null hypotheses at any conventional significance level. These results alleviate the potential concern that the GDA-I model may be weakly identified, since the 25 SIZE/BM portfolio 
betas with respect to the GDA-I factor are both individually and jointly significant, and they exhibit significant cross-sectional dispersion in the statistical sense too. Hence, we conclude that the 25 SIZE/BM portfolio returns significantly covary with the GDA-I SDF, and that these covariances exhibit a significant cross-sectional dispersion, reflecting the dispersion across portfolio premia.

\section{B. Sensitivity Analysis with respect to the Disappointment Thresh- old Coefficient}

In this section, we examine how sensitive is the explanatory ability of the GDA-I model with respect to the disappointment threshold coefficient $d_{2}$, which together with the consumption growth moments determines the GDA-I certainty equivalent for consumption growth (see equation (5)). To this end, we arbitrarily set this coefficient equal to $d_{2} \pm$ std.error $\left(d_{2}\right)$, based on the estimates of $d_{2}(=-0.770)$ and std.error $\left(d_{2}\right)(=0.256)$ for the 25 SIZE/BM portfolios from Panel A of Table 2. Each of these two alternative values for $d_{2}$ yields a different certainty equivalent, and hence a different set of disappointment consumption events.

Using each of these two modified disappointment indicators, we re-estimate the corresponding betas for the 25 SIZE/BM portfolios, and re-examine their explanatory ability with respect to the annual portfolio premia. Panel A of Figure 7 contains the scatterplot of these portfolio premia versus their GDA-I betas, where the modified GDA-I factor has been determined using a disappointment threshold coefficient equal to $d_{2}+\operatorname{std}$.error $\left(d_{2}\right)(=-0.513)$. In this case, we get 21 disappointment consumption years in the 1933-2012 sample period, and the cross-sectional $R^{2}$ of the modified GDA-I betas with respect to the $25 \mathrm{SIZE} / \mathrm{BM}$ portfolio premia is $82.2 \%$. Moreover, the implied DA coefficient is 2.9 .

Panel B of Figure 7 contains the scatterplot of the 25 SIZE/BM portfolio premia versus their GDA-I betas, where the modified GDA-I factor has been determined using a disappointment threshold coefficient equal to $d_{2}-\operatorname{std}$.error $\left(d_{2}\right)(=-1.026)$. In this case, we get

only 7 disappointment consumption years. For this set of disappointment events, the cross- 
sectional $R^{2}$ of the modified GDA-I betas with respect to the portfolio premia is $79 \%$, and the implied DA coefficient is 4.8 .

This sensitivity analysis leads to some interesting conclusions. First, the explanatory power of the GDA-I model in the SIZE/BM sample remains quite high for a wide range of values of the disappointment threshold coefficient. Therefore, its successful empirical performance in our benchmark results is not particularly sensitive to the characterization as disappointing or not of those consumption growth observations that lie marginally around the GDA-I certainty equivalent (see Figure 4). This result is also consistent with the findings in Section VI regarding the performance of the restricted DA-I model across equity portfolios.

Second, an alternative way to interpret these results is that the set of the 7 lowest consumption growth years $(1937,1946,1973,1979,1990$, and 2007-2008), which coincides with the set of the disappointment events derived when the threshold coefficient is equal to -1.026, goes a long way in explaining the cross-sectional dispersion in portfolio premia. Finally, the price of disappointment risk estimated from each of these two alternative sets of disappointment consumption events remains relatively stable around the benchmark estimates reported in Table 2 .

It should be also noted that in Section A11 of the Internet Appendix, we conduct a number of further tests to examine the importance of key parameters of the GDA-I model. Specifically, to examine the importance of persistence in consumption growth, we firstly estimate a variant of the GDA-I model, where we impose an i.i.d. consumption growth process, i.e., $\phi_{c}=0$ in equation (4). Secondly, to assess the importance of the time-variation in the GDA-I threshold, we alternatively estimate indicator models where the disappointment threshold is time-invariant, and it is specified in an ad hoc fashion. In particular, we estimate an indicator model where the disappointment threshold is the unconditional mean of consumption growth $\left(\mathbf{1}\left\{\Delta c_{t+1} \leq \mu_{c}\right\}\right)$ as well as a model where the threshold is zero consumption growth $\left(\mathbf{1}\left\{\Delta c_{t+1} \leq 0\right\}\right)$. Finally, to highlight the role of the DA parameter $\tilde{\theta}$, we also estimate a variant of the GDA-I model, where we restrict the price of disappointment 
risk to be equal to 1 , i.e., $\tilde{\theta}=1$ in equation (4).

The results from these tests show that these alternative models perform much worse relative to our benchmark GDA-I model, yielding higher average pricing errors and lower cross-sectional $R^{2}$ s. Based on these findings, we conclude that the success of the GDA-I model should be attributed to a theoretically consistent time-varying reference point (see equation (5)) and a DA parameter that is greater than 1.

\section{Placebo Indicators}

Last but not least, we address the potential concern that the high explanatory power of the GDA-I model may be spuriously driven by the fact that the proposed factor is an indicator function. In particular, we examine whether a randomly generated (placebo) indicator could also yield a similarly high explanatory power, and hence whether our benchmark results are driven by "luck". To this end, we generate 1,000,000 time series, each consisted of 80 observations drawn from a Bernoulli distribution, containing exactly 67 zeros and 13 ones, and hence characterized by the same mean and variance as the GDA-I factor extracted from the cross-section of the $25 \mathrm{SIZE} / \mathrm{BM}$ portfolios in Table 2. Subsequently, we estimate the betas of the $25 \mathrm{SIZE} / \mathrm{BM}$ portfolios with respect to each of these placebo indicators, and run a cross-sectional regression (without intercept) of the annual portfolio premia on the corresponding placebo indicator betas.

Figure 8 shows the histogram of the cross-sectional $R^{2}$ s yielded by the placebo indicators, whereas the red vertical line indicates the $R^{2}(=90.1 \%)$ of the actual GDA-I factor. It is evident that the placebo indicators have a dismally low explanatory power with respect to the $25 \mathrm{SIZE} / \mathrm{BM}$ portfolio premia. In fact, only 15 out of the 1,000,000 placebo indicators $(=0.0015 \%)$ yield a cross-sectional $R^{2}$ that is equal to or greater than the one of the GDAI factor. Hence, we can confidently reject at any conventional significance level the null hypothesis that the explanatory power of the proposed factor is driven by "luck". ${ }^{14}$

\footnotetext{
${ }^{14}$ Another potential concern is that the disappointment indicator may be highly persistent, leading to
} 


\section{Conclusion}

Kocherlakota (1996) argues that to improve the performance of consumption-based models (at least) one of the following three assumptions needs to be relaxed: (i) CRRA preferences, (ii) market completeness, (iii) transaction costs. In this paper, we relax the CRRA assumption and propose a single-factor asset pricing model based on an indicator function of aggregate consumption growth being less than its certainty equivalent. This certainty equivalent is derived from generalized disappointment aversion preferences, and it is located approximately one standard deviation below the expected consumption growth.

Our single-factor model can sufficiently explain the cross-section of expected returns for the size, value, profitability, investment, reversal, corporate bond, Treasury bond, and equity index option portfolios. In terms of relative performance, the proposed model outperforms traditional asset pricing models (CCAPM, CAPM). Moreover, the fit of our model is at least as good as the fit of the Fama and French (1993) three-factor model, and its performance is comparable to the one of the five-factor specification (Fama and French (2015)). In fact, our single-factor model can also explain the premia that the five Fama and French (2015) factors yield. Finally, the estimated prices of disappointment risk are plausible and much more stable across test assets and frequencies relative to the risk aversion coefficient estimates derived from the CCAPM.

Collectively, our results indicate that risk premia are, to a large extent, compensation for exposure to disappointment (i.e., downside) consumption risk, and challenge the overreaction hypothesis suggested by a number of previous studies. Our findings also highlight that disappointment aversion plays a crucial role in understanding the cross-section of expected returns from a consumption-based perspective, and question the effectiveness of the secondorder risk aversion framework that is commonly used in consumption-based asset pricing.

spurious inference. The autocorrelation coefficient estimate for the disappointment indicator extracted from the cross-section of the $25 \mathrm{SIZE} / \mathrm{BM}$ portfolios in Table 2 is $0.09(p$-value $=0.395)$. Similar results hold for the other cross-sections, indicating that the GDA-I factor exhibits insignificant persistence. 


\section{References}

Ang, A., G. Bekaert, and J. Liu, 2005, "Why Stocks May Disappoint," Journal of Financial Economics, 76(3), 471-508.

Baker, M., and J. Wurgler, 2006, "Investor Sentiment and the Cross-section of Stock Returns," Journal of Finance, 61(4), 1645-1680.

Barberis, N., M. Huang, and T. Santos, 2001, "Prospect Theory and Asset Prices," Quarterly Journal of Economics, 116(1), 1-53.

Boguth, O., and L.-A. Kuehn, 2013, "Consumption Volatility Risk," Journal of Finance, 68(6), 25892615.

Bonomo, M., R. Garcia, N. Meddahi, and R. Tédongap, 2011, "Generalized Disappointment Aversion, Long-Run Volatility Risk, and Asset Prices," Review of Financial Studies, 24(1), $82-122$.

Breeden, D. T., 1979, "An Intertemporal Asset Pricing Model with Stochastic Consumption and Investment Opportunities," Journal of Financial Economics, 7(3), 265-296.

Bryzgalova, S., 2015, "Spurious Factors in Linear Asset Pricing Models," Working paper.

Burnside, C., 2011, "The Cross-Section of Foreign Currency Risk Premia and Consumption Growth Risk: Comment," American Economic Review, 101(7), 3456-3476.

Campbell, J., 2003, "Consumption-Based Asset Pricing," in Handbook of the Economics of Finance. Elsevier, Amsterdam, vol. 1B, pp. 801-885.

Choi, S., R. Fisman, D. Gale, and S. Kariv, 2007, "Consistency and Heterogeneity of Individual Behavior Under Uncertainty," American Economic Review, 97(5), 1921-1938.

Cochrane, J., 2001, Asset pricing. Princeton University Press, Princeton, NJ. 
Constantinides, G. M., J. C. Jackwerth, and A. Savov, 2013, "The Puzzle of Index Option Returns," Review of Asset Pricing Studies, 3(1), 229-257.

Dahlquist, M., A. Faragó, and R. Tédongap, 2017, "Asymmetries and Portfolio Choice," Review of Financial Studies, 30(2), 667-702.

DeBondt, W. F., and R. Thaler, 1985, "Does the Stock Market Overreact?," Journal of Finance, 40(3), 793-805.

Delikouras, S., 2017, "Where's the Kink? Disappointment Events in Consumption Growth and Equilibrium Asset Prices," Review of Financial Studies, 30(8), 2851-2889.

Epstein, L. G., and S. E. Zin, 1989, "Substitution, Risk Aversion, and the Temporal Behavior of Consumption and Asset Returns," Econometrica, 57(4), 937-969.

— , 1990, "First-Order Risk Aversion and the Equity Premium Puzzle," Journal of Monetary Economics, 26(3), 387-407.

—_ 2001, "The Independence Axiom and Asset Returns," Journal of Empirical Finance, $8(5), 537-572$.

Fama, E. F., and K. R. French, 1993, "Common Risk Factors in the Returns on Stocks and Bonds," Journal of Financial Economics, 33(1), 3-56.

— , 2015, "A Five-Factor Asset Pricing Model," Journal of Financial Economics, 116(1), $1-22$.

Faragó, A., and R. Tédongap, 2017, "Downside Risks and the Cross-Section of Asset Returns," Journal of Financial Economics, Forthcoming.

Gill, D., and V. Prowse, 2012, "A Structural Analysis of Disappointment Aversion in a Real Effort Competition," American Economic Review, 102(1), 469-503.

Gul, F., 1991, "A Theory of Disappointment Aversion," Econometrica, 59(3), 667-686. 
Hansen, L. P., 1982, "Large Sample Properties of Generalized Method of Moments Estimators," Econometrica, 50(4), 1029-1054.

Hansen, L. P., and K. J. Singleton, 1982, "Generalized Instrumental Variables Estimation of Non-Linear Rational Expectations Models," Econometrica, 50(5), 1269-1286.

Harvey, C. R., Y. Liu, and H. Zhu, 2015, “... and the Cross-Section of Expected Returns," Review of Financial Studies, 29(1), 5-68.

Hou, K., C. Xue, and L. Zhang, 2016, "A Comparison of New Factor Models," Working paper.

Jagannathan, R., and Y. Wang, 2007, "Lazy Investors, Discretionary Consumption, and the Cross-Section of Stock Returns," Journal of Finance, 62(4), 1623-1661.

Jegadeesh, N., and S. Titman, 1993, "Returns to Buying Winners and Selling Losers: Implications for Stock Market Efficiency," Journal of Finance, 48(1), 65-91.

Kocherlakota, N., 1996, "The Equity Premium: It's Still a Puzzle," Journal of Economic Literature, 34(1), 42-71.

Lakonishok, J., A. Shleifer, and R. W. Vishny, 1994, "Contrarian investment, extrapolation and risk," Journal of Finance, 49(5), 1541-1578.

Lettau, M. L., and S. C. Ludvigson, 2001, "Consumption, Aggregate Wealth, and Expected Stock Returns," Journal of Finance, 56(3), 815-849.

Lettau, M. L., M. Maggiori, and M. Weber, 2014, "Conditional Risk Premia in Currency Markets and Other Asset Classes," Journal of Financial Economics, 114(2), 197-225.

Lewellen, J., S. Nagel, and J. Shanken, 2010, "A Skeptical Appraisal of Asset Pricing Tests," Journal of Financial Economics, 96(2), 175-194. 
Liu, L. X., T. M. Whited, and L. Zhang, 2009, "Investment-Based Expected Stock Returns," Journal of Political Economy, 117(6), 1105-1139.

Mehra, R., and E. C. Prescott, 1985, "The Equity Premium: A Puzzle," Journal of Monetary Economics, 15(2), 145-161.

Merton, R. C., 1973, “An Intertemporal Capital Asset Pricing Model,” Econometrica, 41(5), $867-887$.

Nozawa, Y., 2012, "Corporate Bond Premia," Working paper.

Ostrovnaya, A., B. R. Routledge, and S. E. Zin, 2006, "Endogenous Countercyclical Risk Aversion and the Cross-Section," Working paper.

Parker, J. A., and C. Julliard, 2005, "Consumption Risk and the Cross-Section of Expected Returns," Journal of Political Economy, 113(1), 185-222.

Rabin, M., 2000, "Risk Aversion and Expected-Utility Theory: A Calibration Theorem," Econometrica, 68(5), 1281-1292.

Routledge, B., and S. Zin, 2010, "Generalized Disappointment Aversion and Asset Prices," Journal of Finance, 65(4), 1303-1332.

Savov, A., 2011, “Asset Pricing with Garbage," Journal of Finance, 76(1), 177-201.

Schreindorfer, D., 2014, "Tails, Fears, and Equilibrium Option Prices," Working paper.

Segal, U., and A. Spivak, 1990, "First Order Versus Second Order Risk Aversion," Journal of Economic Theory, 51(1), 111-125.

Welch, I., and A. Goyal, 2008, "A comprehensive Look at the Empirical Performance of Equity Premium Prediction," Review of Financial Studies, 21(4), 1455-1508.

Yogo, M., 2006, "A Consumption-Based Explanation of Expected Stock Returns," Journal of Finance, 61(2), 539-580. 


\section{Figures}

\section{FIGURE 1 Sample and Fitted Risk Premia for Equity Portfolios: Equal-Weighted Returns}

Figure 1 shows sample and fitted annual risk premia for the 25 size/book-to-market portfolios (Panel A), the 25 size/operating profitability portfolios (Panel B), the 25 size/investment portfolios (Panel C), and the 10 long-term reversal portfolios (Panel D). All portfolios are equal-weighted. Fitted risk premia are estimated according to the expression in equation (12) for the GDA-I,CCAPM,FF3, and NBER discount factors. Estimation results are shown in Table 2. The sample period is from 1933 to 2012, with the exception of the operating profitability and investment portfolios that start in 1964 .

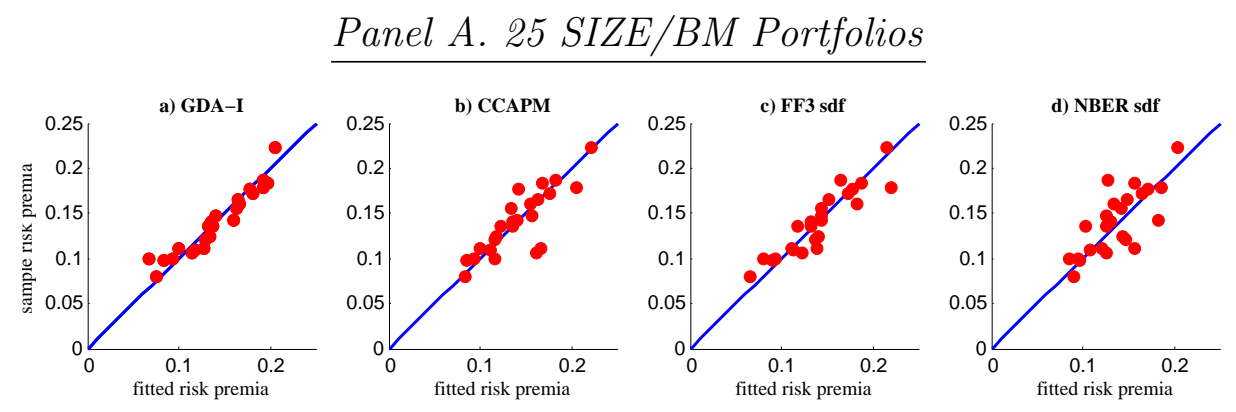

Panel B. 25 SIZE/OP Portfolios
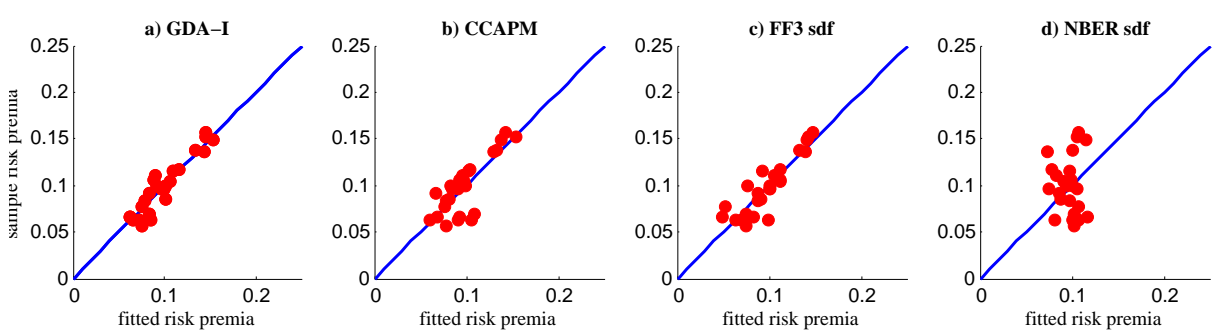

Panel C. 25 SIZE/INV Portfolios
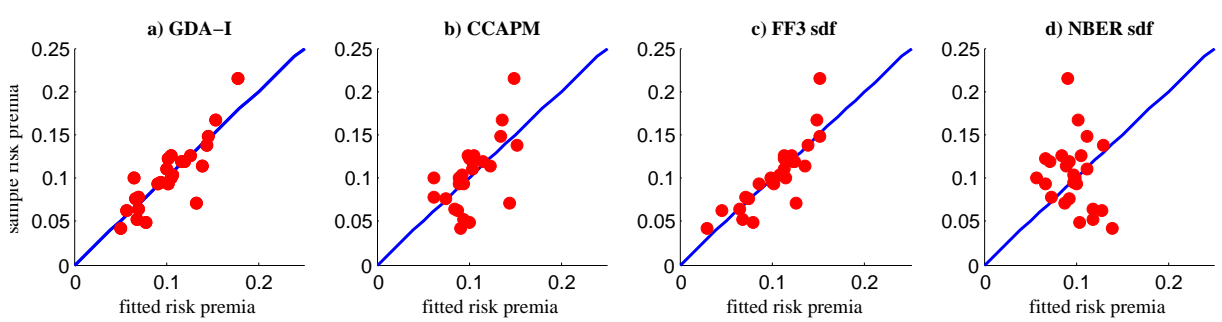

Panel D. 10 LTR Portfolios
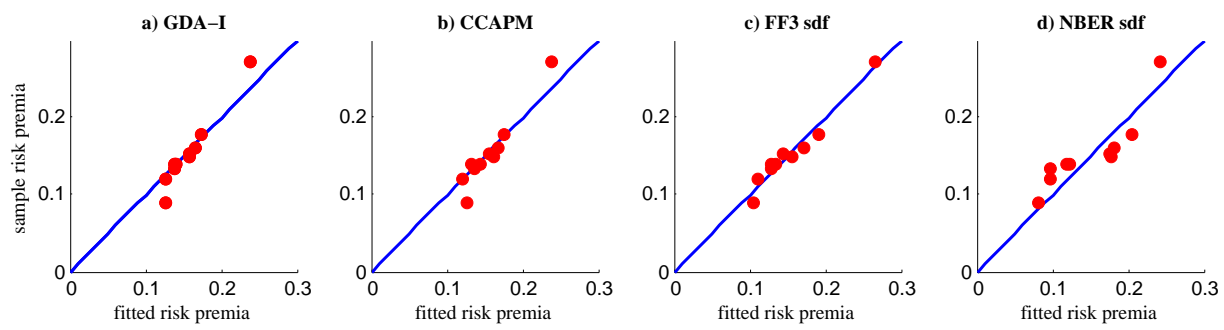


\section{FIGURE 2 Sample and Fitted Risk Premia for Equity Portfolios: Value-Weighted returns}

Figure 2 shows sample and fitted annual risk premia for the 25 size/book-to-market portfolios (Panel A), the 25 size/operating profitability portfolios (Panel B), the 25 size/investment portfolios (Panel C), and the 10 long-term reversal portfolios (Panel D). All portfolios are value-weighted. Fitted risk premia are estimated according to the expression in equation (12) for the GDA-I, CCAPM, FF3, and NBER discount factors. Estimation results are shown in Table 3. The sample period is from 1933 to 2012, with the exception of the operating profitability and investment portfolios that start in 1964.

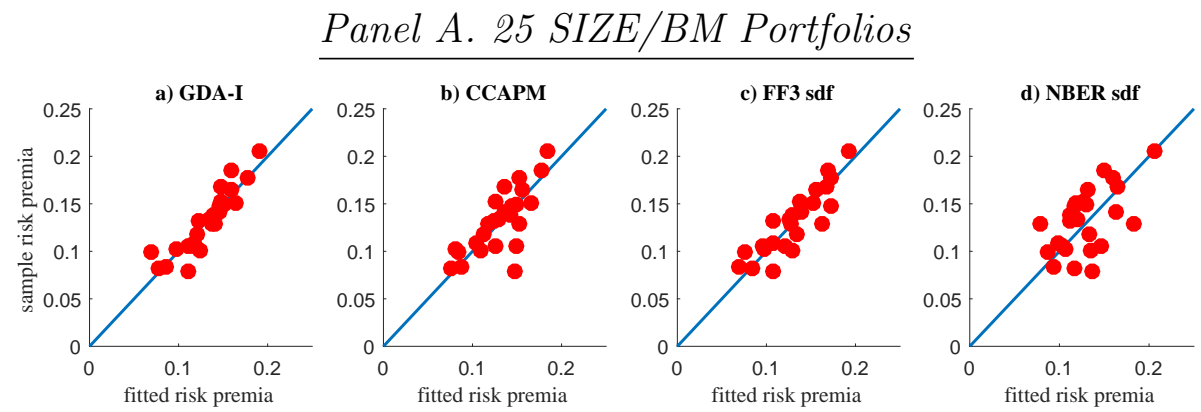

Panel B. 25 SIZE/OP Portfolios
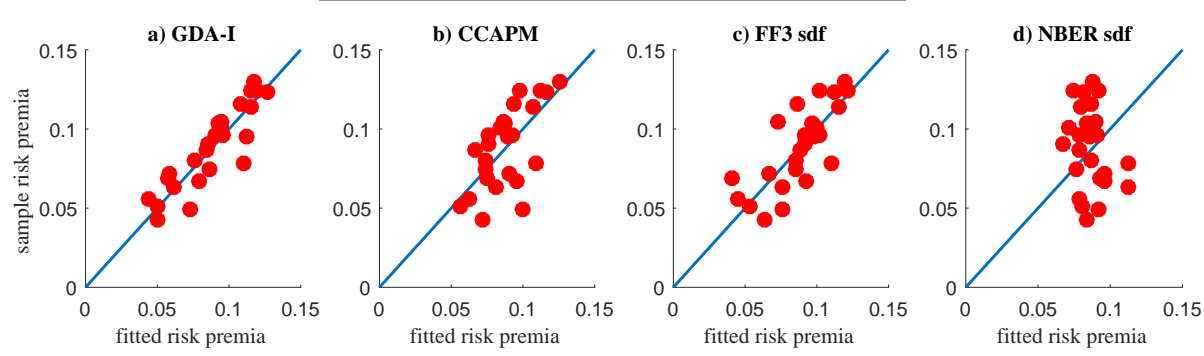

Panel C. 25 SIZE/INV Portfolios
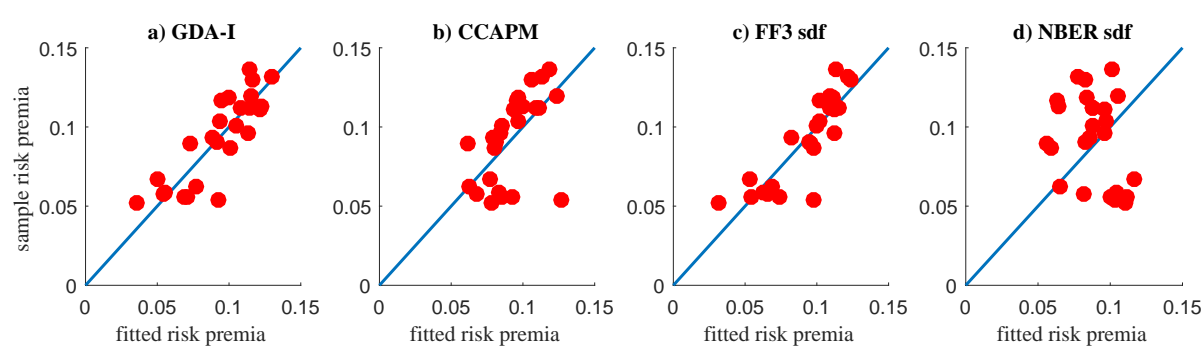

Panel D. 10 LTR Portfolios
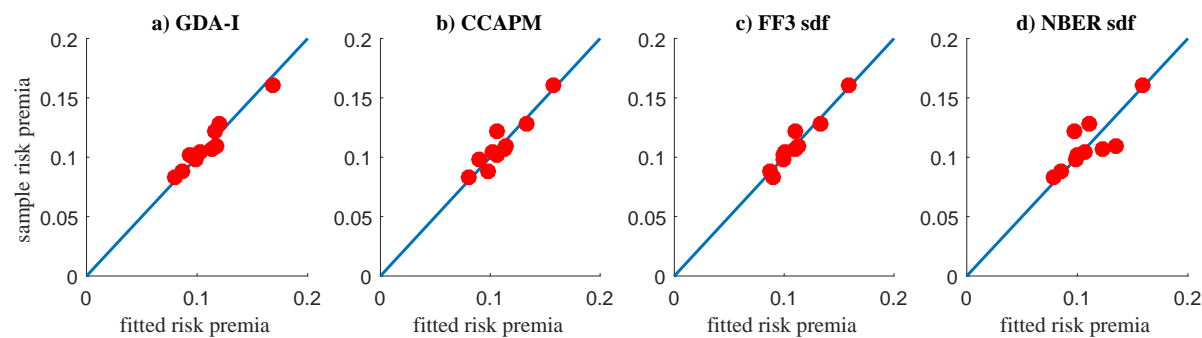


\section{FIGURE 3 Sample and Fitted Risk Premia for Alternative Asset Classes}

Figure 3 shows sample and fitted annual risk premia for the 5 corporate bond portfolios of Nozawa (2012) constructed on the basis of bonds' credit ratings (Panel A), the 6 Fama Treasury bond portfolios sorted on maturity (Panel B), the 6 equity index option portfolios of Constantinides et al. (2013) (Panel C), and the joint cross-section of the above portfolios together with the 6 Fama-French SIZE/BM portfolios (Panel D). Each cross-section also includes the equity market portfolio. Fitted risk premia are estimated according to the expression in equation (12) for the $G D A-I, C C A P M, F F 3$, and $N B E R$ discount factors. The corresponding estimation results are shown in Table 4. The sample period is 1976-2009 for the corporate bond portfolios, 1952-2012 for the Treasury bond portfolios, 1987-2011 for the equity index option portfolios, and 1987-2009 for the joint cross-section.

\section{Panel A. 5 Corporate Bond Portfolios}
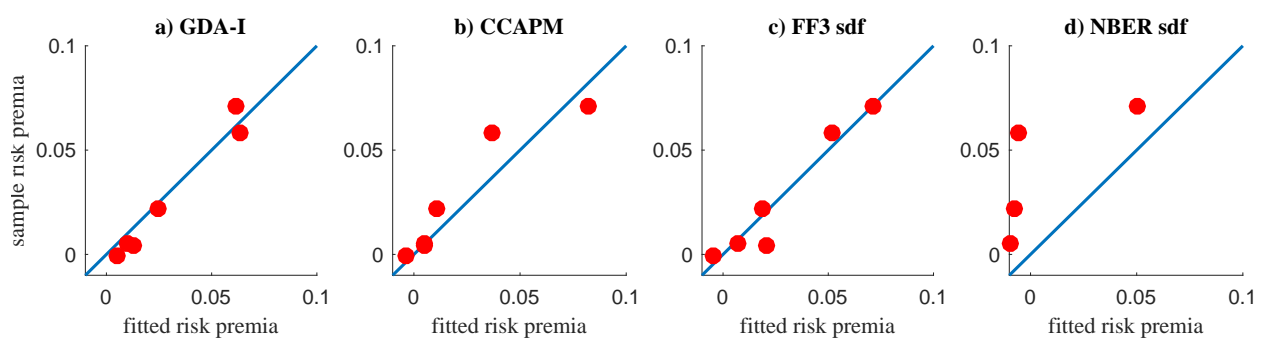

Panel B. 6 Treasury Bond Portfolios
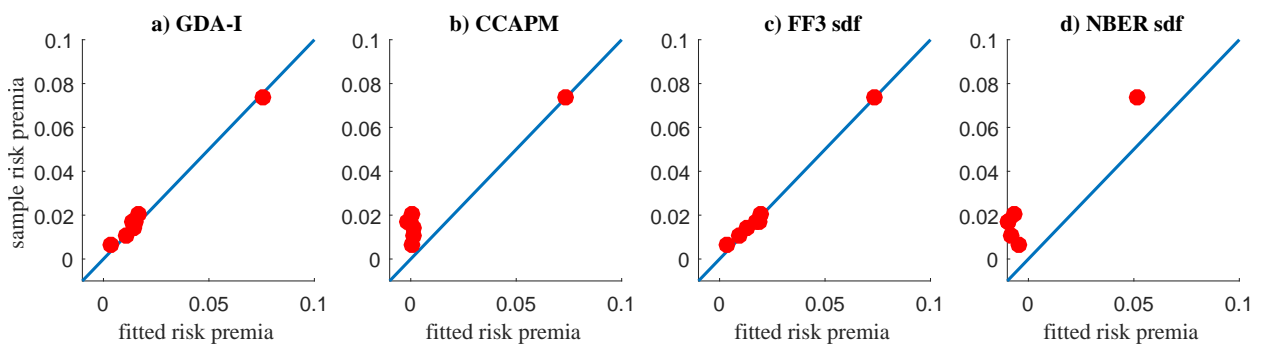

Panel C. 6 Equity Index Option Portfolios
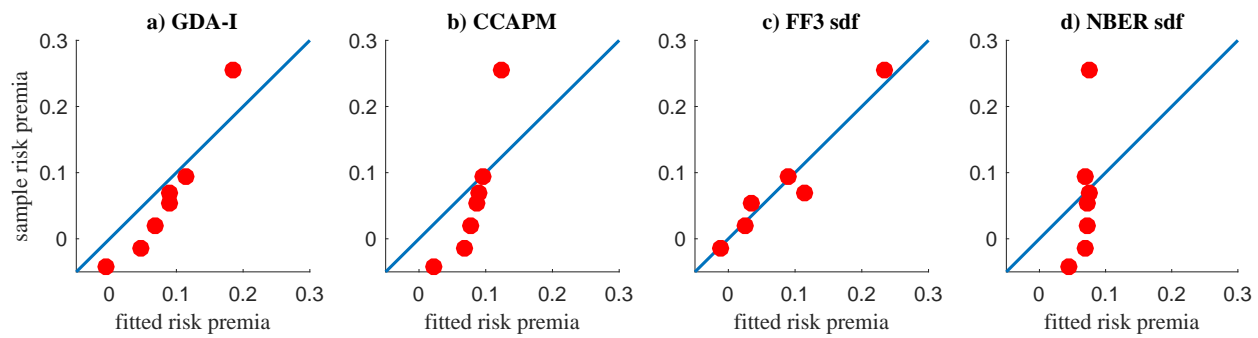

Panel D. Joint Cross-Section
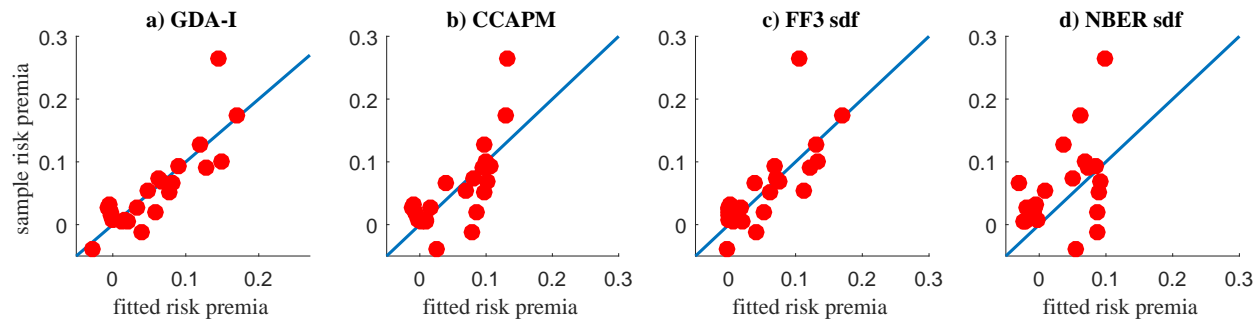


\section{FIGURE 4 Consumption Growth, Disappointment Events, and NBER Recessions}

Figure 4 shows annual disappointment events in consumption growth for the GDA-I discount factor of equation (4). Disappointment events are determined using the estimation results for the 25 size/bookto-market portfolios reported in Panel A of Table 2. The solid line denotes consumption growth, and the dashed line is the time-varying GDA-I certainty equivalent of consumption growth from equation (5). Disappointment events are highlighted by ellipses, and shaded areas are NBER recessions. The sample period is 1933 - 2012 .

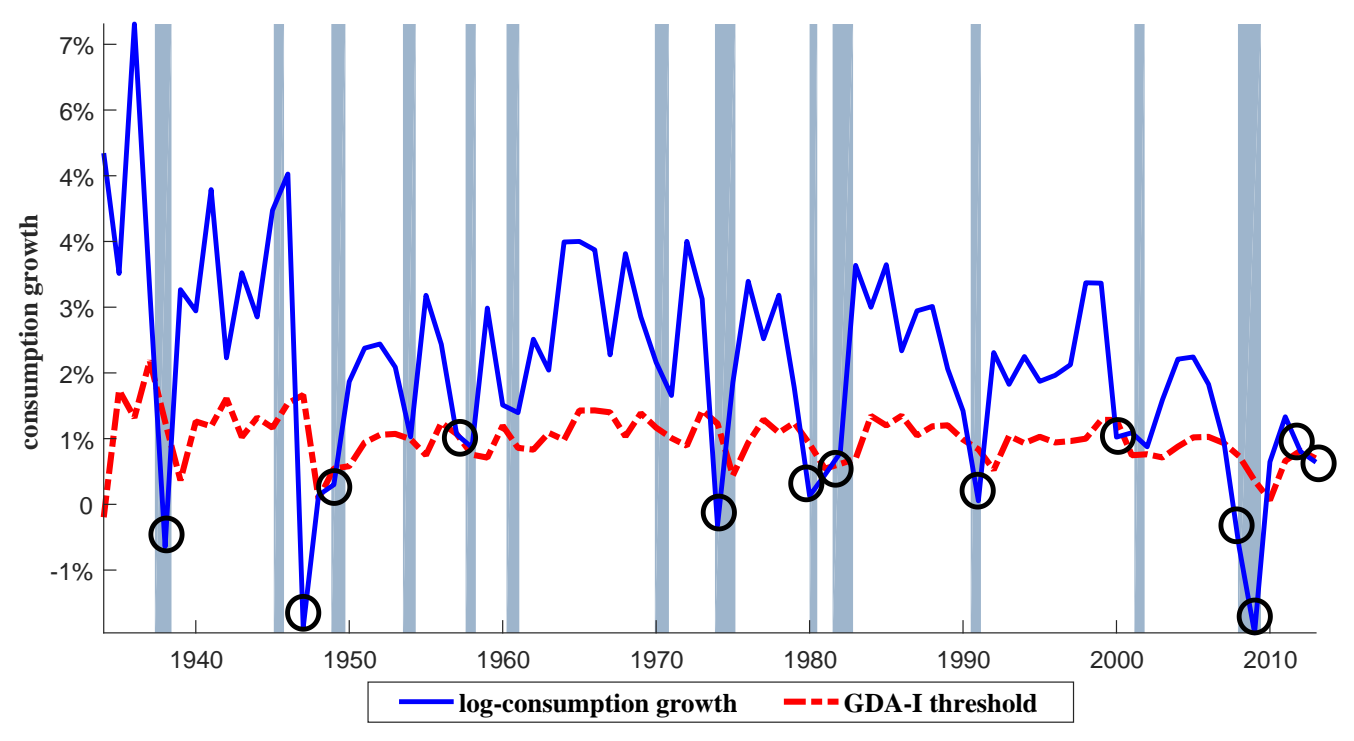




\section{FIGURE 5 Premia vs. GDA-I Betas for the 25 SIZE/BM Port- folios}

Figure 5 plots sample annual premia versus time-series betas estimated with respect to the GDA-I factor for the set of the 25 size/book-to-market portfolios. The GDA-I factor is determined using the estimation results for the 25 size/book-to-market portfolios reported in Panel A of Table 2. $R^{2}$ is computed from the cross-sectional regression of portfolio premia on GDA-I factor betas without intercept. The sample period is $1933-2012$.

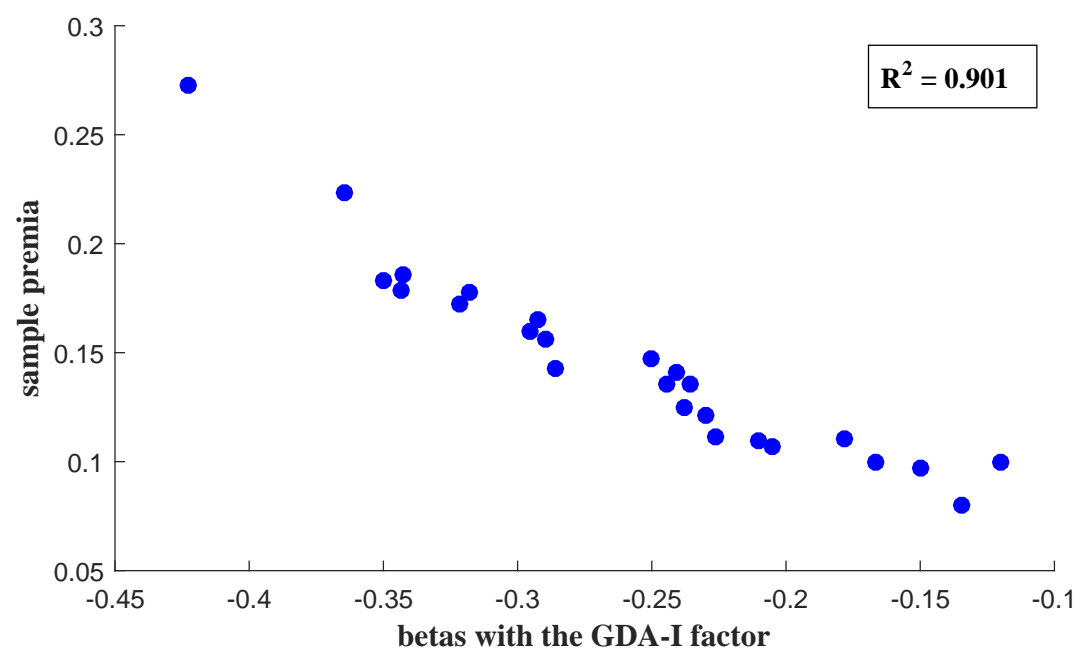




\section{FIGURE 6 Premia vs. GDA-I Betas for the Five Fama-French Factors}

Figure 6 plots sample annual premia versus time-series betas estimated with respect to the GDA-I factor for the five Fama and French (2015) factors. The GDA-I factor is determined using the estimation results for the 25 SIZE/BM portfolios reported in Panel A of Table 2. $R^{2}$ is computed from the cross-sectional regression of factor premia on GDA-I factor betas without intercept. The sample period for the excess market, SMB, and HML factors is 1933 - 2012, whereas the sample period for the RMW and CMA factors is 1964-2012.

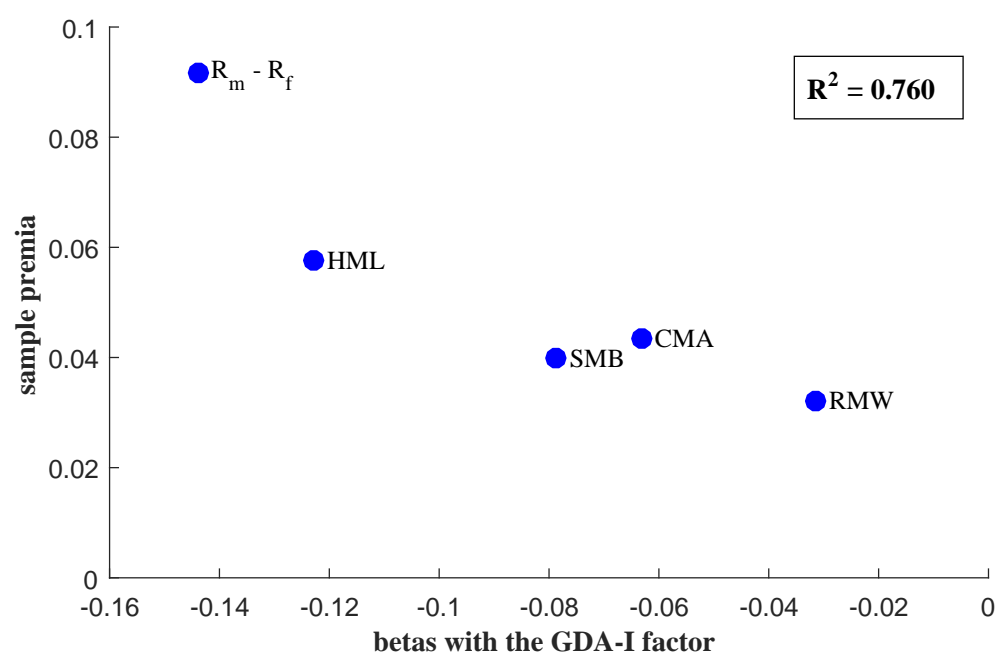




\section{FIGURE 7 Sensitivity Analysis for the Disappointment Thresh- old Coefficient}

Figure 7 plots sample annual premia versus time-series betas estimated with respect to a modified GDA-I factor for the set of 25 equal-weighted SIZE/BM. In Panel A, the modified GDA-I factor is defined relative to the certainty equivalent for consumption growth given by equation (5), and computed using a disappointment threshold coefficient equal to $d_{2}+$ std. error $\left(d_{2}\right)(=-0.513)$. In Panel B, the corresponding modified GDA-I factor is defined using a disappointment threshold coefficient equal to $d_{2}-$ std. error $\left(d_{2}\right)(=-1.026)$. The estimates of $d_{2}(=-0.770)$ and std. error $\left(d_{2}\right)(=0.256)$ are taken from Panel A of Table 2 for the 25 SIZE/BM portfolios. $R^{2}$ is computed from the cross-sectional regression of portfolio premia on GDA-I factor betas without intercept. The sample period is $1933-2012$.

\section{Panel A. Disappointment Threshold Coefficient: $d_{2}+$ std. error $\left(d_{2}\right)$}

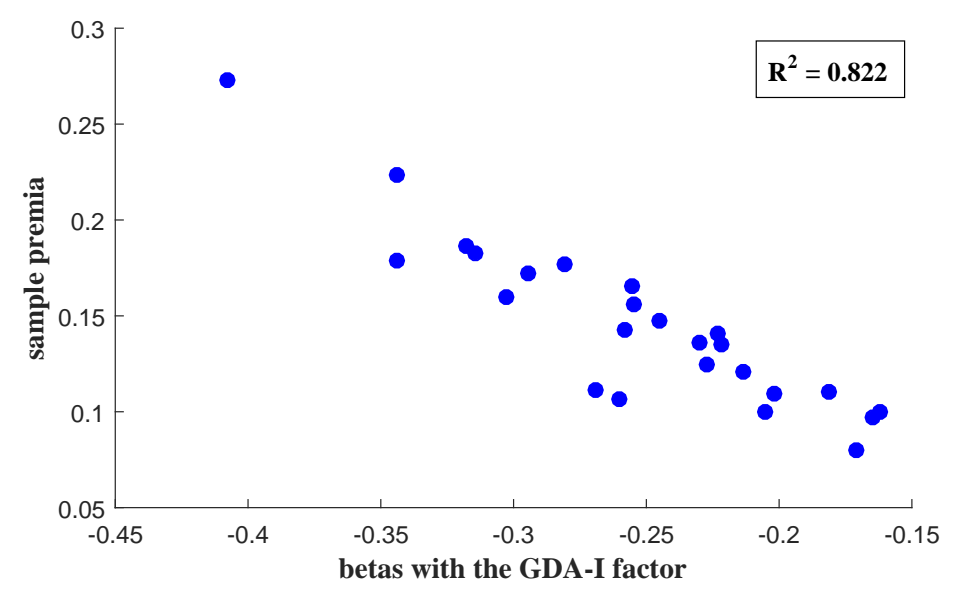

Panel B. Disappointment Threshold Coefficient: $d_{2}-$ std. error $\left(d_{2}\right)$

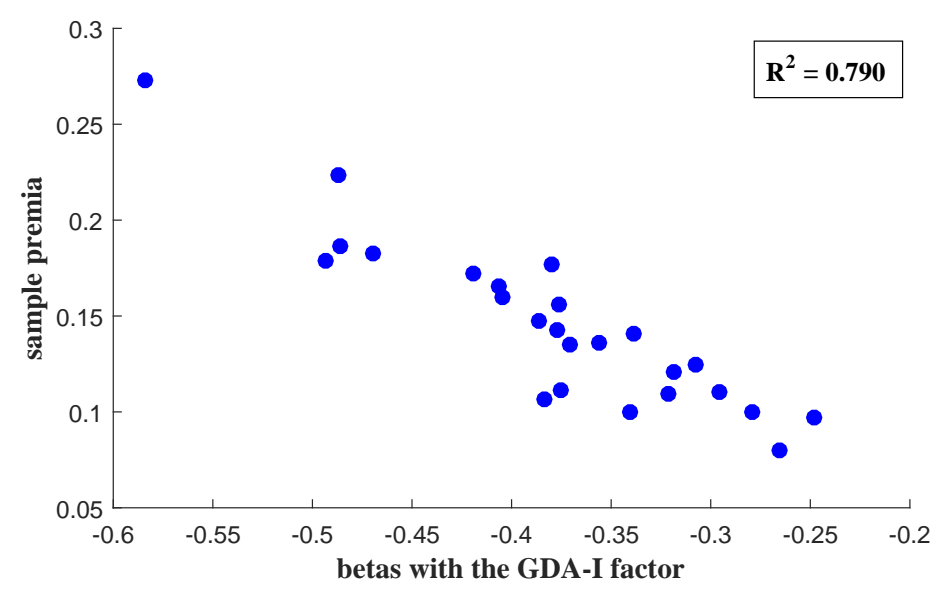




\section{FIGURE 8 Explanatory Power of Placebo Indicators}

Figure 8 shows the histogram of cross-sectional $R^{2}$ s yielded by a no-intercept regression of the annual premia of the 25 equal-weighted SIZE/BM portfolios on their betas estimated with respect to a placebo indicator. Each of the 1,000,000 placebo indicators that we generate consists of 80 observations drawn from a Bernoulli distribution, containing exactly 67 zeros and 13 ones, and thus is characterized by the same mean and variance as the GDA-I factor extracted from the cross-section of the 25 SIZE/BM portfolios. The vertical dashed line indicates the corresponding cross-sectional $R^{2}$ yielded by the actual GDA-I factor $\left(R^{2}=0.901\right)$.

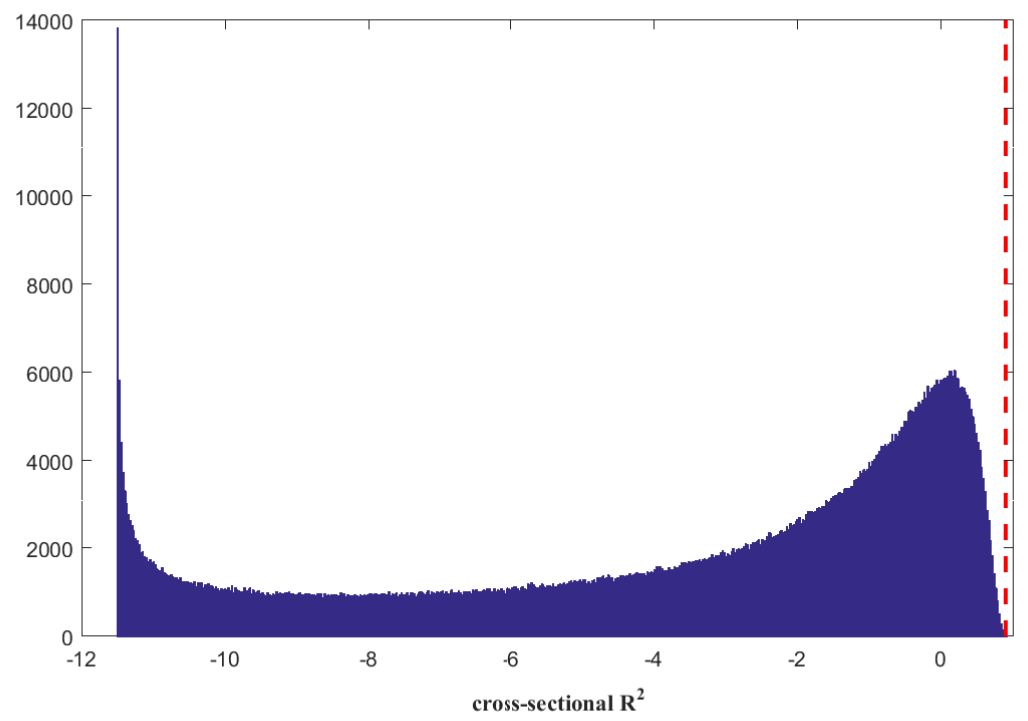




\section{Tables}

\section{TABLE 1 Summary Statistics}

Table 1 shows summary statistics of annual excess returns for a selection of the portfolios used in this study. We consider the following portfolio sorts: the 25 size/book-to-market portfolios (SIZE/BM), the 25 size/operating profitability portfolios (SIZE/OP), the 25 size/investment portfolios (SIZE/INV), the 10 long-term reversal portfolios (LTR), the 5 corporate bond portfolios of Nozawa (2012) constructed on the basis of bonds' credit ratings (CBOND), the 6 Fama Treasury bond portfolios sorted on maturity (TBOND), and the 6 equity index option portfolios of Constantinides et al. (2013) (OPTION). Panel A shows summary statistics for equal-weighted equity portfolio returns, Panel B shows statistics for value-weighted equity portfolio returns, and Panel C shows the corresponding statistics for non-equity asset classes. The sample period for the SIZE/BM and LTR portfolios is from 1933 to 2012, whereas SIZE/OP and SIZE/INV portfolios are available since 1964. The sample period for the corporate bond portfolios is from 1976 to 2009, for the Treasury bond portfolios is from 1952 to 2012, and for the equity index option portfolios is from 1987 to 2011.

\begin{tabular}{|c|c|c|c|c|c|c|c|c|}
\hline & \multicolumn{2}{|c|}{25 SIZE/BM } & \multicolumn{2}{|c|}{$25 \mathrm{SIZE} / \mathrm{OP}$} & \multicolumn{2}{|c|}{25 SIZE/INV } & \multicolumn{2}{|c|}{10 LTR } \\
\hline & SIZE1/BM5 & SIZE5/BM1 & SIZE1/OP1 & SIZE5/OP5 & SIZE1/INV1 & SIZE5/INV5 & LTR1 & LTR10 \\
\hline Average & 27.29 & 7.99 & 14.87 & 7.67 & 21.53 & 4.15 & 27.13 & 9.02 \\
\hline St. Dev. & 48.64 & 19.91 & 41.13 & 19.42 & 44.19 & 23.95 & 52.78 & 26.90 \\
\hline
\end{tabular}

Panel B. Value-Weighted Equity Portfolios

\begin{tabular}{|c|c|c|c|c|c|c|c|c|}
\hline & \multicolumn{2}{|c|}{$25 \mathrm{SIZE} / \mathrm{BM}$} & \multicolumn{2}{|c|}{25 SIZE/OP } & \multicolumn{2}{|c|}{25 SIZE/INV } & \multicolumn{2}{|c|}{10 LTR } \\
\hline & SIZE1/BM5 & SIZE5/BM1 & SIZE1/OP1 & SIZE5/OP5 & SIZE1/INV1 & SIZE5/INV5 & LTR1 & LTR10 \\
\hline Average & 24.17 & 11.98 & 13.13 & 12.15 & 18.85 & 10.47 & 19.68 & 12.48 \\
\hline St. Dev. & 36.90 & 19.35 & 33.70 & 18.42 & 34.01 & 23.20 & 35.46 & 24.86 \\
\hline
\end{tabular}

$\underline{\text { Panel C. Alternative Asset Classes }}$

\begin{tabular}{|c|c|c|c|c|c|c|}
\hline & \multicolumn{2}{|c|}{5 CBOND } & \multicolumn{2}{|c|}{6 TBOND } & \multicolumn{2}{|c|}{6 OPTION } \\
\hline & CBOND1 & CBOND5 & TBOND1 & TBOND6 & OTM_CALL & OTM_PUT \\
\hline $\begin{array}{l}\text { Average } \\
\text { St. Dev. }\end{array}$ & $\begin{array}{c}-0.08 \\
6.10\end{array}$ & $\begin{array}{c}5.79 \\
15.10\end{array}$ & $\begin{array}{l}0.05 \\
0.94\end{array}$ & $\begin{array}{l}0.22 \\
6.82\end{array}$ & $\begin{array}{c}1.94 \\
14.96\end{array}$ & $\begin{array}{l}25.49 \\
26.46\end{array}$ \\
\hline
\end{tabular}




\section{TABLE 2 GMM Results for Annual Portfolio Returns: Equal- Weighted Portfolios}

Table 2 shows GMM results for different equal-weighted portfolio sorts and asset pricing models at the annual frequency. For this set of tests, we estimate consumption growth moments, the DA coefficient $\tilde{\theta}$, and the disappointment threshold $d_{2}$ for the GDA-I model from equation (4) using the augmented GMM system from equation (13). We consider four equalweighted portfolio sorts as test assets: the 25 size/book-to-market portfolios (Panel A), the 25 size/operating profitability portfolios (Panel B), the 25 size/investment portfolios (Panel C), and the 10 long-term reversal portfolios (Panel D). GDA-I is the disappointment aversion discount factor from equation (4), and $C C A P M$ is the consumption-based discount factor from equation (6). $C A P M$ is the market model from (7). FF3 and $F F 5$ are the Fama-French three- and five-factor models in equations (8) and (9), respectively. $N B E R S D F$ is the recession-based discount factor from equation (10). GDA_IND is the disappointment indicator. $\mu_{c}, \sigma_{c}^{2}$, and $\phi_{c} \sigma_{c}^{2}$ denote the consumption growth mean, variance, and autocovariance $(\times 100)$, respectively. CONS is the aggregate consumption growth, $M K T$ is the excess market return, $S M B$ is the size factor, $H M L$ is the value factor, $R M W$ is the profitability factor, $C M A$ is the investment factor, and NBER_IND is the NBER recession indicator. $\tilde{\alpha}$ is the risk aversion parameter in the CCAPM. t-statistics are shown in parentheses. $\chi^{2}$, dof, and $p$ are the first-stage $\chi^{2}$-test (Hansen (1982)), degrees of freedom, and $p$-value that all moment conditions are jointly zero. $R M S E$ and $R^{2}$ are the root mean square error $(\times 100)$ and cross-sectional $R$-square, respectively. The sample period is 1933-2012. The sample for the five-factor Fama-French model, the operating profitability, and investment portfolios begins in 1964.

\begin{tabular}{|c|c|c|c|c|c|c|c|c|c|c|c|c|c|}
\hline \multicolumn{7}{|c|}{ PANEL A. 25 SIZE/BM } & \multicolumn{7}{|c|}{ PANEL C. 25 SIZE/INV } \\
\hline & GDA-I & CCAPM & CAPM & FF3 & FF5 & NBER SDF & & GDA-I & CCAPM & CAPM & FF3 & FF5 & NBER SDF \\
\hline $\operatorname{GDA} \_I N D(\tilde{\theta})$ & $\begin{array}{l}4.126 \\
(4.207)\end{array}$ & & & & & & GDA_IND $(\tilde{\theta})$ & $\begin{array}{c}3.448 \\
(2.477)\end{array}$ & & & & & \\
\hline$d_{2}$ & $\begin{array}{c}-0.770 \\
(-3.006)\end{array}$ & & & & & & $d_{2}$ & $\begin{array}{c}-0.584 \\
(-0.031)\end{array}$ & & & & & \\
\hline$\mu_{c}$ & $\begin{array}{c}2.168 \\
(12.542)\end{array}$ & & & & & & $\mu_{c}$ & $\begin{array}{c}1.945 \\
(10.496)\end{array}$ & & & & & \\
\hline$\sigma_{c}^{2}$ & $\begin{array}{c}0.023 \\
(5.128)\end{array}$ & & & & & & $\sigma_{c}^{2}$ & $\begin{array}{c}0.016 \\
(56.847)\end{array}$ & & & & & \\
\hline$\phi_{c} \sigma_{c}^{2}$ & $\begin{array}{c}0.005 \\
(0.868)\end{array}$ & & & & & & $\phi_{c} \sigma_{c}^{2}$ & $\begin{array}{c}0.010 \\
(2.316)\end{array}$ & & & & & \\
\hline $\operatorname{CONS}(\tilde{\alpha})$ & & $\begin{array}{l}57.331 \\
(3.499)\end{array}$ & & & & & $\operatorname{CONS}(\tilde{\alpha})$ & & $\begin{array}{l}91.068 \\
(1.701)\end{array}$ & & & & \\
\hline MKT & & & $\begin{array}{r}2.935 \\
(4.781)\end{array}$ & $\begin{array}{l}2.043 \\
(2.375)\end{array}$ & $\begin{array}{l}3.191 \\
(2.218)\end{array}$ & & MKT & & & $\begin{array}{l}2.889 \\
(2.785)\end{array}$ & $\begin{array}{l}2.841 \\
(2.010)\end{array}$ & $\begin{array}{c}3.713 \\
(2.512)\end{array}$ & \\
\hline SMB & & & & $\begin{array}{c}0.335 \\
(0.309)\end{array}$ & $\begin{array}{l}1.912 \\
(1.242)\end{array}$ & & SMB & & & & $\begin{array}{l}1.242 \\
(0.921)\end{array}$ & $\begin{array}{c}2.992 \\
(1.707)\end{array}$ & \\
\hline HML & & & & $\begin{array}{c}3.026 \\
(3.079)\end{array}$ & $\begin{array}{l}-0.473 \\
(-0.153)\end{array}$ & & HML & & & & $\begin{array}{l}6.946 \\
(4.281)\end{array}$ & $\begin{array}{c}-4.664 \\
(-0.760)\end{array}$ & \\
\hline RMW & & & & & $\begin{array}{l}0.967 \\
(0.308)\end{array}$ & & RMW & & & & & $\begin{array}{c}4.686 \\
(1.138)\end{array}$ & \\
\hline CMA & & & & & $\begin{array}{c}9.321 \\
(2.080)\end{array}$ & & CMA & & & & & $\begin{array}{l}14.868 \\
(1.811)\end{array}$ & \\
\hline NBER_IND & & & & & & $\begin{array}{l}9.157 \\
(1.053)\end{array}$ & NBER_IND & & & & & & $\begin{array}{c}4.642 \\
(1.188)\end{array}$ \\
\hline $\begin{array}{l}\chi^{2} \\
\text { dof } \\
p\end{array}$ & $\begin{array}{c}28.795 \\
23 \\
0.187\end{array}$ & $\begin{array}{c}87.580 \\
24 \\
0\end{array}$ & $\begin{array}{c}97.940 \\
24 \\
0\end{array}$ & $\begin{array}{c}62.460 \\
22 \\
0\end{array}$ & $\begin{array}{c}42.570 \\
20 \\
0.002\end{array}$ & $\begin{array}{c}5.543 \\
24 \\
1.000\end{array}$ & $\begin{array}{l}\chi^{2} \\
d o f \\
p\end{array}$ & $\begin{array}{c}31.137 \\
23 \\
0.119\end{array}$ & $\begin{array}{c}49.241 \\
24 \\
0.001\end{array}$ & $\begin{array}{c}131.615 \\
24 \\
0\end{array}$ & $\begin{array}{c}64.842 \\
22 \\
0\end{array}$ & $\begin{array}{c}57.750 \\
20 \\
0\end{array}$ & $\begin{array}{c}15.146 \\
24 \\
0.916\end{array}$ \\
\hline $\begin{array}{l}R M S E \\
R^{2}\end{array}$ & $\begin{array}{l}1.345 \\
0.901\end{array}$ & $\begin{array}{l}2.107 \\
0.758\end{array}$ & $\begin{array}{l}2.973 \\
0.519\end{array}$ & $\begin{array}{l}1.648 \\
0.852\end{array}$ & $\begin{array}{l}1.563 \\
0.821\end{array}$ & $\begin{array}{l}2.358 \\
0.697\end{array}$ & $\begin{array}{l}R M S E \\
R^{2}\end{array}$ & $\begin{array}{l}1.952 \\
0.743\end{array}$ & $\begin{array}{l}3.028 \\
0.383\end{array}$ & $\begin{array}{l}3.967 \\
-0.057\end{array}$ & $\begin{array}{l}2.020 \\
0.725\end{array}$ & $\begin{array}{l}1.696 \\
0.806\end{array}$ & $\begin{array}{c}4.770 \\
-0.529\end{array}$ \\
\hline \multicolumn{7}{|c|}{ PANEL B. 25 SIZE $/ O P$} & \multicolumn{7}{|c|}{ PANEL D. 10 LTR } \\
\hline & GDA-I & CCAPM & CAPM & FF3 & FF5 & NBER SDF & & GDA-I & CCAPM & CAPM & FF3 & FF5 & NBER SDF \\
\hline GDA_IND $(\tilde{\theta})$ & $\begin{array}{c}3.809 \\
(1.710)\end{array}$ & & & & & & GDA_IND $(\tilde{\theta})$ & $\begin{array}{c}4.327 \\
(2.912)\end{array}$ & & & & & \\
\hline$d_{2}$ & $\begin{array}{l}-0.480 \\
(-2.004)\end{array}$ & & & & & & $d_{2}$ & $\begin{array}{c}-0.752 \\
(-4.682)\end{array}$ & & & & & \\
\hline$\mu_{c}$ & $\begin{array}{c}1.945 \\
(10.494)\end{array}$ & & & & & & $\mu_{c}$ & $\begin{array}{c}2.168 \\
(12.542)\end{array}$ & & & & & \\
\hline$\sigma_{c}^{2}$ & $\begin{array}{c}0.016 \\
(4.717)\end{array}$ & & & & & & $\sigma_{c}^{2}$ & $\begin{array}{c}0.023 \\
(5.128)\end{array}$ & & & & & \\
\hline$\phi_{c} \sigma_{c}^{2}$ & $\begin{array}{c}0.010 \\
(2.309)\end{array}$ & & & & & & $\phi_{c} \sigma_{c}^{2}$ & $\begin{array}{c}0.005 \\
(0.868)\end{array}$ & & & & & \\
\hline $\operatorname{CONS}(\tilde{\alpha})$ & & $\begin{array}{l}88.188 \\
(1.672)\end{array}$ & & & & & $\operatorname{CONS}(\tilde{\alpha})$ & & $\begin{array}{l}62.493 \\
(3.352)\end{array}$ & & & & \\
\hline MKT & & & $\begin{array}{c}2.793 \\
(2.698)\end{array}$ & $\begin{array}{l}2.430 \\
(1.797)\end{array}$ & $\begin{array}{l}2.546 \\
(2.051)\end{array}$ & & MKT & & & $\begin{array}{l}3.189 \\
(4.875)\end{array}$ & $\begin{array}{l}1.042 \\
(0.695)\end{array}$ & $\begin{array}{c}1.558 \\
(0.418)\end{array}$ & \\
\hline SMB & & & & $\begin{array}{c}1.452 \\
(1.258)\end{array}$ & $\begin{array}{c}2.037 \\
(2.024)\end{array}$ & & SMB & & & & $\begin{array}{l}2.205 \\
(0.830)\end{array}$ & $\begin{array}{l}10.133 \\
(1.844)\end{array}$ & \\
\hline HML & & & & $\begin{array}{c}5.156 \\
(1.839)\end{array}$ & $\begin{array}{c}0.805 \\
(0.267)\end{array}$ & & HML & & & & $\begin{array}{l}3.067 \\
(1.330)\end{array}$ & $\begin{array}{l}-14.952 \\
(-1.052)\end{array}$ & \\
\hline RMW & & & & & $\begin{array}{c}3.523 \\
(1.824)\end{array}$ & & RMW & & & & & $\begin{array}{l}12.369 \\
(1.121)\end{array}$ & \\
\hline CMA & & & & & $\begin{array}{c}2.142 \\
(0.596)\end{array}$ & & CMA & & & & & $\begin{array}{l}31.899 \\
(1.248)\end{array}$ & \\
\hline NBER_IND & & & & & & $\begin{array}{c}4.527 \\
(1.183)\end{array}$ & NBER_IND & & & & & & $\begin{array}{c}9.797 \\
(1.054)\end{array}$ \\
\hline $\begin{array}{l}\chi^{2} \\
d o f \\
p\end{array}$ & $\begin{array}{c}15.506 \\
23 \\
0.875\end{array}$ & $\begin{array}{c}30.481 \\
24 \\
0.169\end{array}$ & $\begin{array}{c}69.366 \\
24 \\
0\end{array}$ & $\begin{array}{c}51.500 \\
22 \\
0\end{array}$ & $\begin{array}{c}36.759 \\
20 \\
0.012\end{array}$ & $\begin{array}{c}15.714 \\
24 \\
0.898\end{array}$ & $\begin{array}{l}\chi^{2} \\
d o f \\
p\end{array}$ & $\begin{array}{c}13.411 \\
8 \\
0.098\end{array}$ & $\begin{array}{c}24.233 \\
9 \\
0.003\end{array}$ & $\begin{array}{c}37.292 \\
9 \\
0\end{array}$ & $\begin{array}{c}25.435 \\
7 \\
0\end{array}$ & $\begin{array}{c}2.763 \\
5 \\
0.736\end{array}$ & $\begin{array}{c}2.943 \\
9 \\
0.966\end{array}$ \\
\hline$R M S E$ & & 1.728 & & 1.338 & 1.016 & 3.247 & $R M S E$ & 1.640 & 1.658 & 2.213 & 0.954 & 0.708 & 2.450 \\
\hline$R^{2}$ & $\begin{array}{l}1.001 \\
0.879\end{array}$ & $\begin{array}{l}1.128 \\
0.660\end{array}$ & 0.187 & $\begin{array}{l}1.7306 \\
0.796\end{array}$ & $\begin{array}{l}1.800 \\
0.882\end{array}$ & $\begin{array}{l}3.247 \\
-0.197\end{array}$ & $R^{2}$ & 0.868 & 0.865 & 0.759 & 0.960 & 0.967 & 0.705 \\
\hline
\end{tabular}




\section{TABLE 3 GMM Results for Annual Portfolio Returns: Value- Weighted Portfolios}

Table 3 shows GMM results for different value-weighted portfolio sorts and asset pricing models at the annual frequency. For this set of tests, we estimate consumption growth moments, the DA coefficient $\tilde{\theta}$, and the disappointment threshold $d_{2}$ for the GDA-I model from equation (4) using the augmented GMM system from equation (13). Table 3 does not report estimation results for the consumption growth moments. We consider four value-weighted portfolio sorts as test assets: the 25 size/book-to-market portfolios (Panel A), the 25 size/operating profitability portfolios (Panel B), the 25 size/investment portfolios (Panel C), and the 10 long-term reversal portfolios (Panel D). GDA-I is the disappointment aversion discount factor and $C C A P M$ is the consumption-based discount factor. $C A P M$ is the market model. $F F 3$ and $F F 5$ are the Fama-French three- and five-factor models. $N B E R S D F$ is the recession-based discount factor. GDA_IND is the disappointment indicator, $C O N S$ is the aggregate consumption growth, $M K T$ is the excess market return, $S M B$ is the size factor, $H M L$ is the value factor, $R M W$ is the profitability factor, $C M A$ is the investment factor, and NBER_IND is the NBER recession indicator. $\tilde{\alpha}$ is the risk aversion parameter in the CCAPM. t-statistics are shown in parentheses. $\chi^{2}$, dof, and $p$ are the first-stage $\chi^{2}$-test, degrees of freedom, and $p$-value that all moment conditions are jointly zero. $R M S E$ and $R^{2}$ are the root mean square error $(\times 100)$ and cross-sectional R-square, respectively. The sample period is 1933-2012. The sample for the five-factor Fama-French model, the operating profitability, and the investment portfolios begins in 1964.

\begin{tabular}{|c|c|c|c|c|c|c|c|c|c|c|c|c|c|}
\hline & GDA-I & CCAPM & CAPM & FF3 & FF5 & NBER SDF & & GDA-I & CCAPM & CAPM & FF3 & FF5 & NBER SDF \\
\hline GDA_IND $(\tilde{\theta})$ & $\begin{array}{c}4.447 \\
(3.593)\end{array}$ & & & & & & GDA_IND $(\tilde{\theta})$ & $\begin{array}{c}3.622 \\
(1.466)\end{array}$ & & & & & \\
\hline$d_{2}$ & $\begin{array}{c}-0.872 \\
(-4.681)\end{array}$ & & & & & & $d_{2}$ & $\begin{array}{l}-0.609 \\
(-5.285)\end{array}$ & & & & & \\
\hline CONS $(\tilde{\alpha})$ & & $\begin{array}{c}56.398 \\
(3.532)\end{array}$ & & & & & $\operatorname{CONS}(\tilde{\alpha})$ & & $\begin{array}{l}84.516 \\
(1.803)\end{array}$ & & & & \\
\hline MKT & & & $\begin{array}{c}2.861 \\
(4.599)\end{array}$ & $\begin{array}{c}2.221 \\
(2.776)\end{array}$ & $\begin{array}{c}3.384 \\
(2.734)\end{array}$ & & MKT & & & $\begin{array}{c}2.726 \\
(2.676)\end{array}$ & $\begin{array}{c}3.335 \\
(2.555)\end{array}$ & $\begin{array}{c}3.606 \\
(2.782)\end{array}$ & \\
\hline SMB & & & & $\begin{array}{l}-0.008 \\
(-0.007)\end{array}$ & $\begin{array}{c}1.470 \\
(1.042)\end{array}$ & & SMB & & & & $\begin{array}{c}0.169 \\
(0.124)\end{array}$ & $\begin{array}{c}0.820 \\
(0.505)\end{array}$ & \\
\hline HML & & & & $\begin{array}{c}2.856 \\
(2.891)\end{array}$ & $\begin{array}{c}0.750 \\
(0.252)\end{array}$ & & HML & & & & $\begin{array}{c}5.785 \\
(3.765)\end{array}$ & $\begin{array}{c}2.246 \\
(0.450)\end{array}$ & \\
\hline RMW & & & & & $\begin{array}{c}4.113 \\
(1.260)\end{array}$ & & RMW & & & & & $\begin{array}{c}2.005 \\
(0.677)\end{array}$ & \\
\hline CMA & & & & & $\begin{array}{c}5.478 \\
(1.470)\end{array}$ & & CMA & & & & & $\begin{array}{c}4.553 \\
(0.809)\end{array}$ & \\
\hline NBER_IND & & & & & & $\begin{array}{c}7.659 \\
(1.192)\end{array}$ & NBER_IND & & & & & & $\begin{array}{c}3.669 \\
(1.489)\end{array}$ \\
\hline$\chi^{2}$ & 34.238 & 104.775 & 120.754 & 100.862 & 71.257 & 7.978 & $\chi^{2}$ & 21.249 & 42.580 & 122.485 & 101.728 & 73.478 & 23.746 \\
\hline dof & 23 & 24 & 24 & 22 & 20 & 24 & dof & 23 & 24 & 24 & 22 & 20 & 24 \\
\hline$p$ & 0.061 & 0 & 0 & 0 & 0 & 0.999 & $p$ & 0.565 & 0.011 & 0 & 0 & 0 & 0.476 \\
\hline$R M S E$ & 1.358 & 2.165 & 2.819 & 1.591 & 1.497 & 2.867 & $R M S E$ & 1.460 & 2.283 & 3.277 & 1.360 & 1.330 & 3.605 \\
\hline$R^{2}$ & 0.827 & 0.561 & 0.256 & 0.763 & 0.754 & 0.231 & $R^{2}$ & 0.707 & 0.286 & -0.471 & 0.746 & 0.757 & -0.780 \\
\hline
\end{tabular}

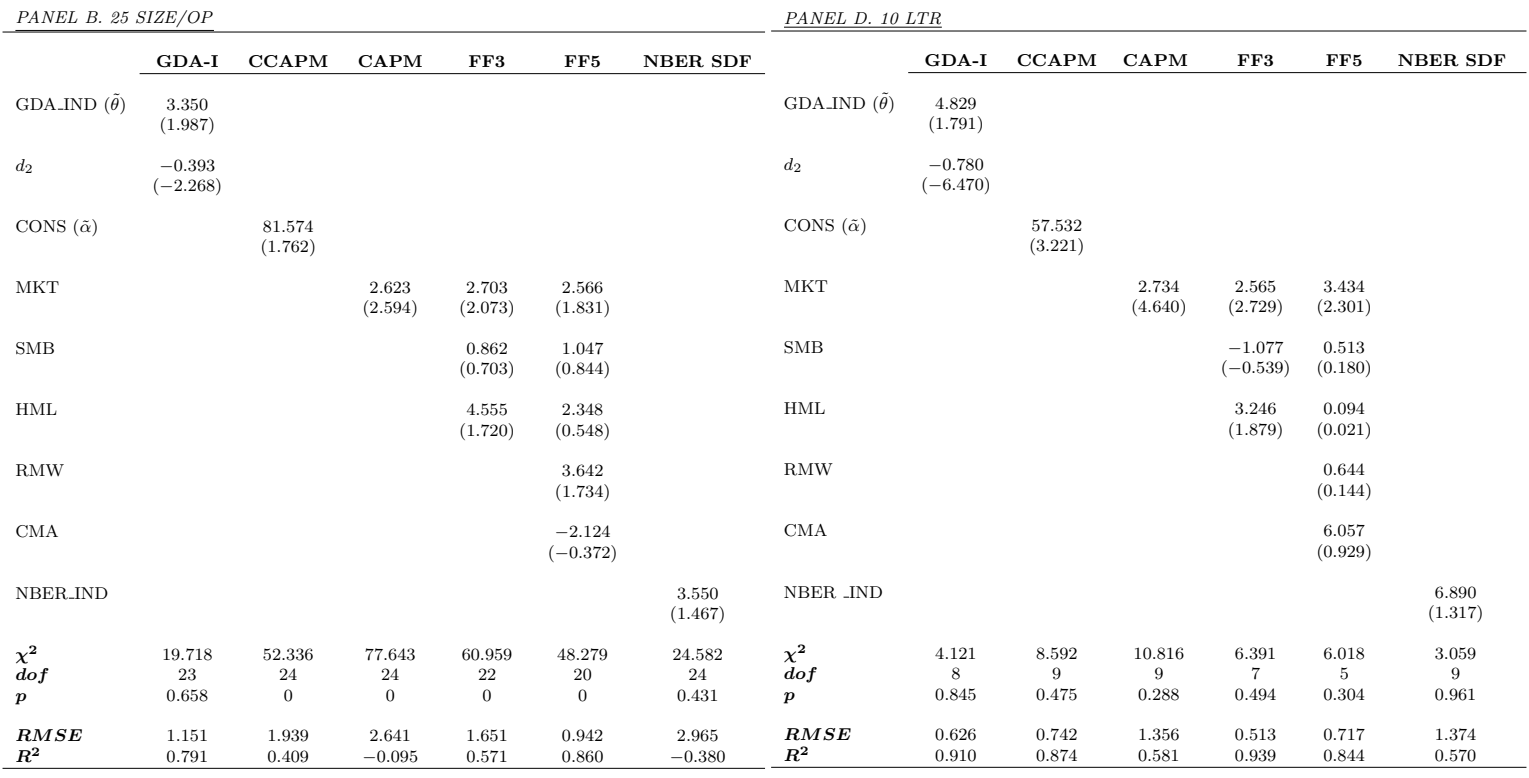




\section{TABLE 4 GMM Results for Alternative Asset Classes}

Table 4 shows GMM results for different asset classes and asset pricing models at the annual frequency. For this set of tests, we estimate consumption growth moments, the DA coefficient $\tilde{\theta}$, and the disappointment threshold $d_{2}$ for the $G D A-I$ model from equation (4) using the augmented GMM system from equation (13). Table 4 does not report estimation results for the consumption growth moments. We consider four sets of portfolios as test assets: the 5 corporate bond portfolios of Nozawa (2012) constructed on the basis of bonds' credit ratings (Panel A), the 6 Fama Treasury bond portfolios sorted on maturity (Panel B), the 6 equity index option portfolios of Constantinides et al. (2013) (Panel C), and a joint cross-section of the above portfolios together with the 6 Fama-French equal-weighted size/book-to-market portfolios (Panel D). In each of these cross-sections, we also include the equity market portfolio as a test asset. $G D A-I$ is the disappointment aversion discount factor and $C C A P M$ is the consumption-based discount factor. $C A P M$ is the market model. $F F 3$ and $F F 5$ are the Fama-French three- and five-factor models. NBER SDF is the recession-based discount factor. GDA_IND is the disappointment indicator, $C O N S$ is the aggregate consumption growth, $M K T$ is the excess market return, $S M B$ is the size factor, $H M L$ is the value factor, $R M W$ is the profitability factor, $C M A$ is the investment factor, and NBER_IND is the NBER recession indicator. $\tilde{\alpha}$ is the risk aversion parameter in the CCAPM. $t$-statistics are shown in parentheses. $\chi^{2}, d o f$, and $p$ are the first-stage $\chi^{2}$-test, degrees of freedom, and $p$-value that all moment conditions are jointly zero. Panel D does not show $t$-statistics or $p$-values for the $\chi^{2}$-test due to the limited time-series observations relative to the number of portfolios. $R M S E$ and $R^{2}$ are the root mean square error ( $\times 100)$ and cross-sectional R-square, respectively. The sample period is 1976-2009 for the corporate bond portfolios, 1952-2012 for the Treasury bond portfolios (1964-2012 in the FF5 model), 1987-2011 for the equity index option portfolios, and 1987-2009 for the joint cross-section.

\begin{tabular}{|c|c|c|c|c|c|c|c|c|c|c|c|c|c|}
\hline & GDA-I & CCAPM & CAPM & FF3 & FF5 & NBER SDF & & GDA-I & CCAPM & CAPM & FF3 & FF5 & NBER SDF \\
\hline GDA_IND $(\tilde{\theta})$ & $\begin{array}{c}3.721 \\
(1.442)\end{array}$ & & & & & & GDA_IND $(\tilde{\theta})$ & $\begin{array}{c}4.433 \\
(1.421)\end{array}$ & & & & & \\
\hline$d_{2}$ & $\begin{array}{c}-0.784 \\
(-4.700)\end{array}$ & & & & & & $d_{2}$ & $\begin{array}{l}-2.054 \\
(-4.271)\end{array}$ & & & & & \\
\hline CONS $(\tilde{\alpha})$ & & $\begin{array}{l}100.531 \\
(1.126)\end{array}$ & & & & & CONS $(\tilde{\alpha})$ & & $\begin{array}{l}77.859 \\
(1.369)\end{array}$ & & & & \\
\hline MKT & & & $\begin{array}{c}2.763 \\
(2.157)\end{array}$ & $\begin{array}{c}5.508 \\
(2.076)\end{array}$ & $\begin{array}{l}18.134 \\
(0.698)\end{array}$ & & MKT & & & $\begin{array}{c}3.115 \\
(1.965)\end{array}$ & $\begin{array}{l}1.757 \\
(0.429)\end{array}$ & $\begin{array}{c}9.963 \\
(0.611)\end{array}$ & \\
\hline SMB & & & & $\begin{array}{c}1.677 \\
(0.380)\end{array}$ & $\begin{array}{c}9.090 \\
(0.498)\end{array}$ & & SMB & & & & $\begin{array}{l}19.776 \\
(1.411)\end{array}$ & $\begin{array}{c}3.198 \\
(0.104)\end{array}$ & \\
\hline HML & & & & $\begin{array}{l}11.052 \\
(1.477)\end{array}$ & $\begin{array}{l}-11.009 \\
(-0.373)\end{array}$ & & HML & & & & $\begin{array}{l}-0.505 \\
(-0.049)\end{array}$ & $\begin{array}{c}4.191 \\
(0.130)\end{array}$ & \\
\hline RMW & & & & & $\begin{array}{l}37.755 \\
(0.540)\end{array}$ & & RMW & & & & & $\begin{array}{c}-7.107 \\
(-0.167)\end{array}$ & \\
\hline CMA & & & & & $\begin{array}{l}48.154 \\
(0.632)\end{array}$ & & CMA & & & & & $\begin{array}{l}44.848 \\
(0.702)\end{array}$ & \\
\hline NBER_IND & & & & & & $\begin{array}{c}2.298 \\
(1.501)\end{array}$ & NBER_IND & & & & & & $\begin{array}{c}2.810 \\
(1.064)\end{array}$ \\
\hline$\chi^{2}$ & 2.755 & 2.415 & 15.090 & 3.117 & 0.026 & 4.462 & $\chi^{2}$ & 12.561 & 44.925 & 28.714 & 3.209 & 0.853 & 17.426 \\
\hline$d o f$ & 4 & 5 & 5 & 3 & 1 & 5 & dof & 5 & 6 & 6 & 4 & 2 & 6 \\
\hline$p$ & 0.599 & 0.789 & 0.009 & 0.373 & 0.871 & 0.484 & $p$ & 0.027 & 0 & 0 & 0.523 & 0.652 & 0.007 \\
\hline$R_{R^{2}}^{R M E}$ & 0.689 & 1.096 & 1.486 & 0.729 & 0.124 & 3.150 & $R M S E$ & 4.500 & 6.919 & 6.964 & 2.107 & 1.762 & 8.511 \\
\hline$R^{2}$ & 0.939 & 0.847 & 0.719 & 0.932 & 0.998 & -0.259 & $R^{2}$ & 0.751 & 0.411 & 0.404 & 0.945 & 0.961 & 0.109 \\
\hline \multicolumn{7}{|c|}{ PANEL B. 6 Treasury Bond Portfolios } & \multicolumn{7}{|c|}{ PANEL D. Joint Cross-Section } \\
\hline & GDA-I & CCAPM & CAPM & FF3 & FF5 & NBER SDF & & GDA-I & CCAPM & CAPM & FF3 & FF5 & NBER SDF \\
\hline GDA_IND $(\tilde{\theta})$ & $\begin{array}{c}4.776 \\
(2.785)\end{array}$ & & & & & & GDA_IND $(\tilde{\theta})$ & 4.120 & & & & & \\
\hline$d_{2}$ & $\begin{array}{l}-0.626 \\
(-1.619)\end{array}$ & & & & & & $d_{2}$ & -1.634 & & & & & \\
\hline CONS $(\tilde{\alpha})$ & & $\begin{array}{l}74.295 \\
(2.016)\end{array}$ & & & & & CONS $(\tilde{\alpha})$ & & 80.403 & & & & \\
\hline MKT & & & $\begin{array}{c}2.243 \\
(2.851)\end{array}$ & $\begin{array}{c}3.040 \\
(0.964)\end{array}$ & $\begin{array}{c}4.168 \\
(0.922)\end{array}$ & & MKT & & & 2.826 & 3.205 & -0.571 & \\
\hline SMB & & & & $\begin{array}{c}5.546 \\
(0.425)\end{array}$ & $\begin{array}{c}3.579 \\
(0.250)\end{array}$ & & SMB & & & & 0.819 & -2.269 & \\
\hline HML & & & & $\begin{array}{l}22.027 \\
(1.099)\end{array}$ & $\begin{array}{l}27.266 \\
(1.217)\end{array}$ & & HML & & & & 4.342 & 13.336 & \\
\hline RMW & & & & & $\begin{array}{l}-7.379 \\
(-0.561)\end{array}$ & & RMW & & & & & -14.478 & \\
\hline CMA & & & & & $\begin{array}{c}-9.685 \\
(-0.398)\end{array}$ & & CMA & & & & & -6.595 & \\
\hline NBER_IND & & & & & & $\begin{array}{c}2.916 \\
(1.180)\end{array}$ & NBER & & & & & & 3.192 \\
\hline$\chi^{2}$ & 8.058 & 25.917 & 36.151 & 2.360 & 0.834 & 15.032 & $\chi^{2}$ & 11.945 & 584.405 & 113.709 & 104.126 & 32.693 & 15.708 \\
\hline dof & 5 & 6 & 6 & 4 & 2 & 6 & dof & 22 & 23 & 23 & 21 & 19 & 23 \\
\hline$p$ & 0.153 & 0 & 0 & 0.669 & 0.657 & 0.020 & $p$ & & & & & & \\
\hline$R M S E$ & 0.242 & 1.370 & 1.375 & 0.154 & 0.153 & 2.290 & RMSE & 3.402 & 4.447 & 4.749 & 4.137 & 3.717 & 6.358 \\
\hline$R^{2}$ & 0.986 & 0.581 & 0.578 & 0.994 & 0.990 & -0.169 & $R^{2}$ & 0.719 & 0.523 & 0.454 & 0.585 & 0.665 & 0.021 \\
\hline
\end{tabular}




\section{TABLE 5 GMM Results for Annual Portfolio Returns: DA-I Model with Restricted GDA Coefficient $(\delta=1)$}

Table 5 shows GMM results for the $D A-I$ model across different test assets at the annual frequency. For these tests, we estimate consumption growth moments and the DA coefficient $\tilde{\theta}$ for the $D A-I$ model using the augmented GMM system specified in equation (13). The specification of the $D A-I$ model is identical to that of the GDA-I model in equation (4). However, in the $D A-I$ model, the disappointment threshold coefficient $d_{2}^{D A-I}$ in equations (4) and (5) is not estimated as a free parameter. Instead, it is computed as an implicit function of the DA coefficient and the consumption growth moments (see equation (A.15) in the Internet Appendix). Table 5 does not report estimation results for the consumption growth moments. In Panel A, we consider four equal-weighted portfolio sorts: the 25 size/book-to-market portfolios, the 25 size/operating profitability portfolios, the 25 size/investment portfolios, and the 10 long-term reversal portfolios. In Panel B, we consider the 5 corporate bond portfolios of Nozawa (2012) constructed on the basis of bonds' credit ratings, the 6 Fama Treasury bond portfolios sorted on maturity, the 6 equity index option portfolios of Constantinides et al. (2013), and a joint cross-section of the above portfolios together with the 6 Fama-French equal-weighted size/book-to-market portfolios. In each of the cross-sections in Panel B, we also include the equity market portfolio as a test asset. $t$-statistics are shown in parentheses. $\chi^{2}, d o f$, and $p$ are the first-stage $\chi^{2}$-test, degrees of freedom, and $p$-value that all moment conditions are jointly zero. The results for the joint cross-section in Panel B do not include $t$-statistics or $p$-values for the $\chi^{2}$-test due to the limited time-series observations relative to the number of portfolios. RMSE and $R^{2}$ are the root mean square error $(\times 100)$ and cross-sectional R-square, respectively. In Panel A, the sample period for the size/book-to-market and long-term reversal portfolios is 1933-2012, whereas the sample for the operating profitability and the investment portfolios begins in 1964. In Panel B, the sample period is 1976-2009 for the corporate bond portfolios, 1952-2012 for the Treasury bond portfolios, 1987-2011 for the equity index option portfolios, and 1987-2009 for the joint cross-section.

Panel A. Equal-Weighted Equity Portfolios

\begin{tabular}{lcccc}
\hline & 25 SIZE/BM & 25 SIZE/OP & 25 SIZE/INV & 10 LTR \\
\cline { 2 - 5 }$\tilde{\theta}$ & 3.090 & 3.485 & 3.510 & 3.253 \\
& $(3.862)$ & $(2.648)$ & $(2.142)$ & $(6.645)$ \\
$d_{2}^{D A-I}$ & -0.548 & -0.581 & -0.583 & -0.563 \\
$\boldsymbol{\chi}^{\mathbf{2}}$ & 35.598 & 43.429 & 79.456 & 13.470 \\
$\boldsymbol{d o f}$ & 24 & 24 & 24 & 9 \\
$\boldsymbol{p}$ & 0.060 & 0.008 & 0 & 0.142 \\
& & & & \\
$\boldsymbol{R M} \boldsymbol{M} \boldsymbol{E}$ & 1.542 & 1.010 & 1.962 & 1.857 \\
$\boldsymbol{R}^{\mathbf{2}}$ & 0.870 & 0.883 & 0.741 & 0.830 \\
& & & & \\
\hline
\end{tabular}

Panel B. Alternative Asset Classes

\begin{tabular}{lcccc}
\hline & $\begin{array}{c}\text { 5 Corporate Bond } \\
\text { Portfolios }\end{array}$ & $\begin{array}{c}\text { 6 Treasury Bond } \\
\text { Portfolios }\end{array}$ & $\begin{array}{c}\text { 6 Equity Index } \\
\text { Option Portfolios }\end{array}$ & $\begin{array}{c}\text { Joint } \\
\text { Cross-Section }\end{array}$ \\
\cline { 2 - 5 }$\tilde{\theta}$ & 3.561 & 4.776 & 3.912 & 2.897 \\
& $(8.159)$ & $(2.192)$ & $(1.362)$ & \\
$d_{2}^{D A-I}$ & -0.587 & -0.681 & -0.616 & -0.526 \\
$\boldsymbol{\chi}^{\mathbf{2}}$ & & & & \\
$\boldsymbol{d} \boldsymbol{f}$ & 6.612 & 14.533 & 8.833 & 23 \\
$\boldsymbol{p}$ & 5 & 6 & 6 & \\
& 0.251 & 0.024 & 0.183 & 3.907 \\
$\boldsymbol{R M} \boldsymbol{S E}$ & 1.584 & 0.242 & 5.457 & 0.630 \\
$\boldsymbol{R}^{\mathbf{2}}$ & 0.681 & 0.986 & 0.633 & \\
\hline
\end{tabular}




\section{TABLE 6 Key Economic Variables During Disappointment and Recession Years}

Table 6 shows averages for key economic and financial variables during disappointment and recession years as well as over the full sample period, 1933-2012. The set of disappointment years is determined using the estimation results for the 25 size/book-to-market portfolios reported in Panel A of Table 2. . $C A Y$ is available since 1945 , unemployment rate is available since 1947, consumer confidence is available since 1961, and sentiment is available since 1965. Factor returns are taken from Kenneth French's website. The economic and financial variables are computed using the updated dataset of Welch and Goyal (2008), with the exception of the unemployment rate, which is taken from the Bureau of Labor Statistics, and the real per capita consumption growth rate, which is from BEA. Consumer confidence is sourced from the University of Michigan survey of consumer confidence, and sentiment is the Baker and Wurgler (2006) index of investor sentiment orthogonalized with respect to a set of macroeconomic conditions.

\begin{tabular}{|c|c|c|c|c|c|}
\hline & Full Sample & Disappointment Years & Non-Disappointment Years & NBER Recession Years & Non-Recession Years \\
\hline Market Premium & $9.16 \%$ & $-3.05 \%$ & $11.52 \%$ & $1.93 \%$ & $10.96 \%$ \\
\hline SMB Premium & $2.12 \%$ & $-5.68 \%$ & $3.63 \%$ & $0.95 \%$ & $2.41 \%$ \\
\hline HML Premium & $9.02 \%$ & $4.23 \%$ & $9.95 \%$ & $8.02 \%$ & $9.28 \%$ \\
\hline S\&P 500 Daily St. Dev. & $15.43 \%$ & $19.22 \%$ & $14.70 \%$ & $19.26 \%$ & $14.48 \%$ \\
\hline Default Spread & $1.12 \%$ & $1.33 \%$ & $1.08 \%$ & $1.55 \%$ & $1.01 \%$ \\
\hline Term Spread & $1.62 \%$ & $0.99 \%$ & $1.74 \%$ & $1.83 \%$ & $1.57 \%$ \\
\hline Real Consumption Growth & $2.21 \%$ & $-0.07 \%$ & $2.65 \%$ & $1.47 \%$ & $2.39 \%$ \\
\hline Earnings Growth & $11.23 \%$ & $3.20 \%$ & $12.78 \%$ & $4.65 \%$ & $12.87 \%$ \\
\hline Net Equity Expansion & $1.52 \%$ & $0.77 \%$ & $1.66 \%$ & $1.48 \%$ & $1.53 \%$ \\
\hline CAY & $0.00 \%$ & $-0.16 \%$ & $0.03 \%$ & $-0.08 \%$ & $0.02 \%$ \\
\hline Inflation Rate & $3.68 \%$ & $6.03 \%$ & $3.23 \%$ & $3.47 \%$ & $3.74 \%$ \\
\hline Change in Inflation & $0.15 \%$ & $1.75 \%$ & $-0.16 \%$ & $-1.13 \%$ & $0.47 \%$ \\
\hline Unemployment & $5.77 \%$ & $5.72 \%$ & $5.78 \%$ & $6.16 \%$ & $5.67 \%$ \\
\hline Change in Unemployment & $0.06 \%$ & $-0.04 \%$ & $0.09 \%$ & $1.25 \%$ & $-0.23 \%$ \\
\hline Unemployment, $\mathrm{t}+1$ & $5.77 \%$ & $6.22 \%$ & $5.68 \%$ & $7.28 \%$ & $5.43 \%$ \\
\hline Change in Unemployment, $\mathrm{t}+1$ & $0.06 \%$ & $0.97 \%$ & $-0.10 \%$ & $1.12 \%$ & $-0.20 \%$ \\
\hline Consumer Confidence & 86.31 & 76.44 & 88.38 & 71.52 & 89.41 \\
\hline \% Change in Consumer Confidence & $0.16 \%$ & $-7.49 \%$ & $1.80 \%$ & $-8.80 \%$ & $2.08 \%$ \\
\hline Sentiment (Orthogonalized) & 0.012 & -0.028 & 0.019 & 0.364 & -0.074 \\
\hline
\end{tabular}




\section{TABLE 7 Identification Tests for GDA-I Betas}

Table 7 presents the results from four Wald tests regarding the joint significance and the cross-sectional dispersion of GDA-I factor betas. We estimate a system of seemingly unrelated regressions (SUR) of the 25 SIZE/BM portfolio excess returns as well as the market portfolio excess return on the GDA-I factor. The GDA-I factor is determined using the estimation results for the 25 SIZE/BM portfolios reported in Panel A of Table 2. Based on these estimates, we conduct the following Wald tests: i) we test whether the 25 portfolio betas are jointly equal to $0\left(H_{0}: \widehat{\beta}_{i}^{G D A-I}=0, \forall i\right)$; ii) we test whether the 25 portfolio GDA-I betas are jointly equal to the market portfolio beta $\left(H_{0}: \widehat{\beta}_{i}^{G D A-I}=\widehat{\beta}_{m}^{G D A-I}, \forall i\right)$; iii) we test whether the 25 portfolio betas are jointly equal to their average estimate $\left(H_{0}: \widehat{\beta}_{i}^{G D A-I}=\overline{\widehat{\beta}}^{G D A-I}, \forall i\right)$; and iv) we test whether the GDA-I beta of the small/value portfolio is equal to that of the big/growth portfolio $\left(H_{0}: \widehat{\beta}_{S 1 B 5}^{G D A-I}=\widehat{\beta}_{S 5 B 1}^{G D A-I}\right)$. Wald and $p$ denote the Wald statistic and the corresponding $p$-value, respectively. The sample period is 1933-2012.

\begin{tabular}{lcccc}
\hline \multicolumn{5}{c}{ Null Hypothesis } \\
\hline \multirow{2}{*}{$\boldsymbol{W}$ ald } & $\widehat{\beta}_{i}^{G D A-I}=0, \forall i$ & $\widehat{\beta}_{i}^{G D A-I}=\widehat{\beta}_{m}^{G D A-I}, \forall i$ & $\widehat{\beta}_{i}^{G D A-I}=\overline{\widehat{\beta}}^{G D A-I}, \forall i$ & $\widehat{\beta}_{S 1 B 5}^{G D A-I}=\widehat{\beta}_{S 5 B 1}^{G D A-I}$ \\
\cline { 2 - 5 } $\boldsymbol{p}$ & 71.68 & 63.32 & 68.97 & 6.24 \\
& 0.000 & 0.000 & 0.000 & 0.002 \\
\hline
\end{tabular}

